\title{
Multiple action options in the context of time: When exams approach, students study more and experience fewer motivational conflicts
}

\author{
Jan Dirk Capelle ${ }^{1} \mathbb{D} \cdot$ Carola Grunschel $^{2} \cdot$ Olga Bachmann $^{1} \cdot$ Miriam Knappe $^{1} \cdot$ Stefan Fries $^{1}$
}

Accepted: 6 October 2021 / Published online: 30 October 2021

(c) The Author(s) 2021

\begin{abstract}
University students' study motivation in a particular moment is shaped by contextual factors such as upcoming exams and conflicts between different action tendencies. We investigated how these two contextual factors are related. Based on the theoretical assumption that students' in-the-moment study motivation increases relative to their motivation for other activities as exams approach, we investigated how students' study activities and their experience of motivational action conflicts develop when exams come closer in time. Using the experience sampling method, we tracked the in-situ activities and conflict experience of 134 first-semester university students over one week and a total of 4995 measurement points just before exams. Multilevel logistic regression revealed that the probability to study increased by $13.9 \%$ and the probability to experience a motivational conflict decreased by $17.5 \%$ each day the exam came closer in time. Multilevel regression showed that motivational conflicts were more intense the closer the exam was in time. Students were generally less likely to experience conflicts while studying and experienced more intense conflicts when the conflicting activity was study related. We discuss that both multiple goals and the temporal distance of relevant events should be considered as relevant contexts shaping the situated motivation of university students.
\end{abstract}

Keywords Motivational conflict $\cdot$ Time $\cdot$ Experience sampling $\cdot$ Situated motivation $\cdot$ Exams

\section{Introduction and theoretical background}

For many students, entering university life is characterized by an unprecedented level of freedom to decide when to do what. While these freedoms have many advantages, they can also be challenging. One challenge is to complete study tasks independently and in due time. Many students tend to "cram" their studying into relatively little time at the end of the semester when exams are written and the majority of coursework is due (Howell et al., 2006; König \& Kleinmann, 2005; Steel, 2007; Taraban et al., 1999). Specifically, study activities become more frequent the closer an upcoming exam is in time (e.g., Howell et al., 2006; Liborius et al., 2019; Taraban et al., 1999). Another challenge is the possibility to choose between multiple available action options

Jan Dirk Capelle

jan.capelle@uni-bielefeld.de

1 Bielefeld University, Universitätsstraße 25, 33615 Bielefeld, Germany

2 University of Münster, Schlossplatz 2, 48149 Münster, Germany in any given moment. Motivational conflicts arise in situations in which students are simultaneously motivated to pursue two or more activities that are mutually exclusive due to limited resources such as time or effort (Hofer \& Fries, 2016; Riediger \& Freund, 2008). For example, a student may attend a friend's birthday party but at the same time feel that they should study for an upcoming exam. Conversely, while studying, a student may feel that they would also like to attend a friend's birthday just taking place. Previous research has shown that students frequently experience motivational conflicts in particular with regard to their study activities (Grund et al., 2015). Motivational conflicts are typically accompanied by impairments in students' performance and well-being (Fries \& Dietz, 2007; Grund et al., 2015; Hofer $\&$ Fries, 2016).

In the present study, we investigated if and how the typical increase in students' study activities close to an exam relates to their experience of motivational conflicts. We thereby aimed to connect two theoretical perspectives that promise to enhance the understanding of student motivation. On the one hand, by considering the temporal distance of an exam, we consider that students' current motivation 
and study behavior may be affected by temporal landmarks such as exams (Peetz \& Wilson, 2013). On the other hand, by considering motivational action conflicts, we consider that students' current motivation may be affected by their multiple goals and available action alternatives (Fries et al., 2008). Crucially, both of these perspectives share a focus on situated motivation in that they assume that in-the-moment study motivation in a specific moment does not arise in a vacuum (e.g., Dietrich et al., 2019; Eccles \& Wigfield, 2020). Rather, they locate the in-the-moment motivation in the context of time and in the context of multiple action alternatives, respectively. We reasoned that this shared reference to situated in-the-moment study motivation could serve as a theoretical common denominator. Specifically, the temporal perspective suggests that more frequent study activities close to an upcoming exam reflect an increased study motivation (e.g., Ainslie, 2010; Steel \& König, 2006; Trope $\&$ Liberman, 2010). The multiple goals perspective suggests that study activities are pursued when in-the-moment study motivation is higher than the current motivation for other available action alternatives (Hofer \& Fries, 2016). Combining these perspectives, we theorized that relative study motivation would be higher the closer an exam was in time and that this would be reflected both in students' study activities and conflict experience over time. The relationship of time and motivational conflicts has barely been considered so far (King \& Gaerlan, 2013). To our knowledge, the present study is the first one that investigates the experience of motivational conflicts as they occur in students' everyday lives in the context of actual passing time.

We conceptualize in-the-moment motivation for a specific activity in the sense of established theories such as situated expectancy value theory (e.g., Dietrich et al., 2017; Eccles \& Wigfield, 2020; Wigfield \& Eccles, 2000) or achievement goal theory (e.g., Elliot, 2006; Elliot \& Covington, 2001). According to these theories, individuals perceive certain motivational characteristics (also called motivational beliefs) of their action alternatives (e.g., a study task) that energize and direct their behavior (e.g., studying) in that moment (e.g., Dietrich et al., 2017; Eccles, 1983; Feltman \& Elliot, 2012). Note that the motivational characteristics of an activity a person perceives in a particular situation are assumed to represent an interaction between a person's characteristics and their specific environmental context (Dweck, 2017; Eccles \& Wigfield, 2020; Fleeson, 2007; Mischel, 1977).

At the same time, we take an indirect approach to assessing study motivation by treating it as a latent construct rather than attempting to measure motivational characteristics directly. While motivational characteristics play a role in both research perspectives on motivation considered here, we saw many uncertainties for measuring the perceived motivational characteristics directly: First, we assume that study motivation relative to the motivation for other activities is crucial in determining which action is pursued (Atkinson, 1974; Hofer \& Fries, 2016) and we are not aware of established instruments that measure relative in-the-moment motivation. Furthermore, motivational characteristics have so far only been assessed over longer time periods (i.e., one semester or more) and seldom with regard to a specific activity or event (Dietrich et al., 2017, 2019; Kosovich et al., 2017; Robinson et al., 2019). In contrast, study behavior has so far only been assessed over shorter time periods (i.e., 1 week) (e.g., Howell et al., 2006; Taraban et al., 1999). Finally, we were concerned that differences in the way motivational characteristics are measured in the two perspectives we considered could distort results. In the current research, we therefore treat motivation as a latent construct and consider actual study behavior and motivational conflict experience appropriate indirect measures of in-the-moment motivation.

\section{Temporal perspective on motivation}

Time as a factor shaping motivation is mostly considered in terms of the temporal proximity of a temporal landmark such as a deadline (Peetz \& Wilson, 2013). We use the term "time" here in this sense.

\section{Theoretical assumptions on the relationship of time and motivation}

All theoretical approaches that are concerned with motivation in the context of time predict increases in study effort the closer a relevant temporal landmark is in time (e.g., Ainslie, 2010; Steel \& König, 2006; Trope \& Liberman, 2010). The two most prominent approaches are temporal discounting and temporal construal.

Temporal discounting describes the tendency to value outcomes higher when they are closer in time and lower when they are further away (Ainslie, 2010; Rubinstein, 2003; Soman et al., 2005). This line of reasoning is wellestablished in the economics and behavioral economics literature and has been incorporated into psychological motivation research via Temporal Motivation Theory (Ainslie, 2010; König \& Kleinmann, 2005; Loewenstein \& Prelec, 1992; MacKillop, et al., 2011; Steel \& König, 2006). Applied to the situations of students, temporal discounting predicts that study activities increase when exams get closer because the relevant outcomes (such as passing or failing an exam) increase in subjective value, resulting in higher current study motivation.

Temporal construal describes the tendency to construe (i.e., mentally represent) distant future events or outcomes in more abstract and simple terms while future events or outcomes closer in time are construed more concretely (Liberman \& Trope, 1998; Liberman et al., 2002; Trope et al., 
2007). In line with temporal discounting, temporal construal theory assumes that temporally more proximate outcomes are subjectively higher valued (Trope $\&$ Liberman, 2010). In addition, it also assumes that more proximate outcomes are also subjectively more controllable which increases motivation to engage in studying (Trope \& Liberman, 2010). Both approaches thus converge on the prediction that study motivation should increase when exams are closer in time. This prediction is also implied in older theories such as the Goal Gradient Hypothesis (Hull, 1932) and Field Theory (Lewin, 1942).

\section{Empirical findings on study activities and study motivation in the context of actual passing time}

As predicted by temporal discounting and temporal construal theories, students often increase the frequency of their study activities toward the end of the semester when exams are written and thereby cram their study activities into relatively little time (Blasiman et al., 2017; König \& Kleinmann, 2005; Liborius et al., 2019; Steel, 2007). Indeed, some students even delay their study activities until the days or even hours before a deadline (Howell et al., 2006; Taraban et al., 1999). In line with the theoretical accounts, the available literature thus unanimously reports increased study activities with passing time.

Few studies have attempted to directly measure study motivation over actual time (e.g., Dresel \& Grassinger, 2013; Kosovich et al., 2017; Robinson et al., 2019). However, these studies mostly assessed motivation with regard to study motivation more generally rather than the motivational characteristics of a specific activity. The studies that assessed motivation for specific tasks or activities did not relate the activity to a specific temporal landmark such as an exam (e.g., Dietrich et al., 2019). Likewise, they observed longer periods of time (i.e., one semester or more) than most of the studies assessing actual study behavior which concentrated on shorter time periods (i.e., around one week) that were monitored more closely (e.g., Howell et al., 2006; Liborius et al., 2019; Taraban et al., 1999). It is therefore doubtful that these findings are applicable to time periods close to an exam and to in-the-moment motivation for a specific activity (Dietrich, et al., 2017; Kosovich et al., 2017).

\section{Summary of the temporal perspective}

Findings on increases of actual study behavior towards the end of the semester match the predictions of theoretical assumptions on time and motivation to pursue activities related to the relevant temporal landmark (i.e., temporal discounting and temporal construal). In the temporal perspective, directly measured study motivation is mostly conceptualized in absolute terms without considering other action alternatives. However, the observed increases in actual study behavior close to exams can also be conceptualized as reflecting an increased study motivation relative to the motivation for other available activities. The multiple goals perspective on motivation takes this perspective.

\section{Multiple goals perspective on motivation}

The theory of motivational action conflicts assumes that students have several goals that they are motivated to pursue (Hofer \& Fries, 2016). It further assumes that pursuing one goal often means neglecting another goal because limited resources such as time or effort prevent individuals from pursuing them in the same moment (Hofer et al., 2007; Riediger \& Freund, 2008). Therefore, students' goals are predicted to regularly come into conflict with another and give rise to motivational conflicts (Hofer \& Fries, 2016). Students experience motivational conflicts frequently which makes them a particularly appropriate group to study motivational conflicts (Grund et al., 2015; Riediger \& Freund, 2008). While previous research has often focused on conflicts between study and leisure activities, conflicts can be experienced between any set of action alternatives, for example between two different study activities (Fries \& Dietz, 2007).

The theory of motivational action conflicts describes the in-the-moment motivation for the available action alternatives mostly in terms of motivational characteristics of the available action alternatives as they are perceived by the individual, for example task values and success expectancies (e.g., Brassler et al., 2016; Eccles, 1983; Grund \& Fries, 2012). It assumes that these motivational characteristics are crucial in determining which activity is pursued as well as if and how a motivational conflict is experienced in a given situation (Hofer \& Fries, 2016). With regard to pursued activities, this implies that a student may abstain from pursuing an activity (e.g., studying) in a specific situation not necessarily because they lack motivation for that activity but because they are more strongly motivated to pursue a different activity (Atkinson, 1974; Hofer \& Fries, 2016). With regard to conflict experience, the theory of motivational action conflicts considers the activity that is not being pursued (i.e., the conflicting activity) and its motivational characteristics to be opportunity costs that affect the pursuit of the focal activity, leading to impairments in students' performance and wellbeing (Flake et al., 2015; Hofer \& Fries, 2016). The concept of motivational interference summarizes these impairments and the motivational processes that are assumed to lead to them (Fries \& Dietz, 2007; Fries et al., 2008; Grund \& Fries, 2014). Previous research on motivational interference has connected the motivational characteristics of both available action alternatives to impairments in both performance and wellbeing (e.g., Brassler et al., 2016; Grund \& Fries, 2012; for an overview, see Hofer \& Fries, 2016). 


\section{Aspects of motivational conflicts (presence, frequency, intensity) and associated impairments}

In addition to the motivational characteristics of the action alternatives involved, three conceptual aspects regarding the experience of motivational conflicts can be distinguished: (i) the presence or absence of a motivational conflict, (ii) the resulting frequency of conflicts over a period of time, and (iii) the intensity of a present conflict (Riediger \& Freund, 2008). All of these characteristics have been related to impairments in students' functioning. The presence of a motivational conflict is associated with impairments in learning and performance such as decreased concentration and persistence (Brassler et al., 2016; Fishbach et al., 2009; Fries \& Dietz, 2007; Fries et al., 2008; Grund et al., 2014; Hofer et al., 2007; Ratelle et al., 2005). Conflict presence is also associated with worse affective wellbeing (Fries \& Dietz, 2007; Grund et al., 2015; Riediger \& Freund, 2008). Consequently, experiencing motivational conflicts more frequently in daily life is associated with negative student outcomes such as lower academic functioning and study satisfaction as well as lower mental health and life satisfaction (Grund et al., 2014; Kuhnle et al., 2010; Ratelle et al., 2005). Likewise, the experience of more intense motivational conflicts is associated with lower academic adaption, lower study satisfaction, and lower study performance (Grund et al., 2015).

\section{Summary of the multiple goals perspective}

In summary, previous research from the multiple goals perspective on motivation has shown that both the motivational characteristics (i.e., the in-the-moment motivation) of the available action alternatives and several aspects of motivational conflicts (i.e., presence, frequency, and intensity) are associated with impairments in student functioning. Furthermore, the theory of motivational action conflicts predicts that the motivational characteristics of action alternatives determine which of the available action alternatives is pursued, how frequently conflicts arise and how intensely they are experienced: The activity with the highest relative in-the-moment motivation should be the one that is being pursued (cf. Atkinson, 1974; Hofer \& Fries, 2016). Conflicts should arise more frequently when students often are similarly motivated for different activities and less frequently when students often have dissimilar levels of motivation for different activities (Hofer \& Fries, 2016). Likewise, the intensity of a conflict should be higher when students' in-the-moment motivation for both available action alternatives is high (cf. Fries et al., 2005; Riediger \& Freund, 2008).

\section{Combining perspectives: Time and motivational conflicts}

Both perspectives share a common theoretical underpinning in their reference to situative in-the-moment motivation for (study) activities, which gives a starting point to combine the two perspectives (e.g., Dietrich et al., 2017; Eccles \& Wigfield, 2020). Our core assumption is that in-the-moment motivation for study activities increases relative to the motivation for other activities right before an exam because the exam is the most relevant temporal landmark during that time period. The increase of current study motivation is suggested by the temporal perspective and indicated by the increase in study activities before a deadline in previous studies (e.g., Howell et al., 2006; Liborius et al., 2019; Taraban et al., 1999). The multiple goals perspective stresses that the current study motivation relative to the motivation for other available action alternatives determines which activity is pursued (e.g., Hofer \& Fries, 2016). A relative increase of in-the-moment study motivation is only implicitly assumed in the temporal perspective as it is mainly focused on changes in activities (e.g., studying) related to the temporal landmark (e.g., an exam). Combining the two perspectives, an upcoming exam should thus be accompanied by an increase of inthe-moment study motivation relative to other activities.

\section{The present study}

As outlined above, an asymmetric increase of in-themoment study motivation over time should be reflected in the probability of study activities, the probability of experiencing a motivational conflict, and the intensity of motivational conflicts as an exam comes closer. In order to investigate if the multiple action options perspective and the temporal perspective on motivation can be combined empirically, we focus on the relationships of time and these aspects of students' behavior and experience. Because an upcoming exam was the relevant temporal landmark in our study, we distinguish between study activities (assumed to be related to the exam) and non-study activities (assumed to be unrelated to the exam) as relevant activity contexts. In addition, we distinguish between main activities and conflicting activities.

On the basis of the preceding considerations, we expected in-the-moment study motivation to increase over time. We considered actual pursuit of study activities as the best indicator for increasing study motivation (relative to other activities) over actual time for the present purpose. Our first hypothesis is therefore: 


\section{Hypothesis 1: study activities}

H1 The probability of study activities increases when an exam comes closer in time (main effect time).

We expected the probability of motivational conflicts to be lower the closer an exam is in time, regardless of activity context. We reasoned that while study activities would increase over time due to an increasing study motivation, students would more actively choose what to do close to the exam and thus experience fewer conflicts even when they were not studying (Hofer \& Fries, 2016). At the same time, we assumed that the asymmetrical motivational effect of an exam on relative study motivation would be salient over the entire time period covered as our sampling period was close to the exams. We therefore assumed that the probability of motivational conflicts would generally be lower when students were studying (cf. Grund \& Fries, 2012; Hofer \& Fries, 2016). Combining the previous two predictions, we further reasoned that the probability to experience a motivational conflict would be lower the closer the exam is in time particularly when students were studying. In summary, our hypotheses regarding the probability of motivational conflicts are:

\section{Hypothesis Set 2: probability of motivational conflicts}

H2a The probability of motivational conflicts is lower the closer an exam is in time (main effect time, regardless of activity context).

H2b The probability of motivational conflicts is lower for study activities compared to non-study activities over the entire sampling period (main effect of the main activity context).

$\mathrm{H} 2 \mathrm{C}$ The probability of motivational conflicts is lower for study activities the closer the exam is in time (interaction time and main activity).

We further reasoned that asymmetric increase of study motivation before the exam would be reflected in the intensity of motivational conflicts. This assumption is based on three considerations. First, motivational conflicts undergo a selection over time: If motivational conflicts become less frequent because the motivation for study activities relative to other activities increases, then motivational conflicts that still occur close to an exam should be characterized by high motivation for both action alternatives. Second, the intensity of a conflict should be higher when students' motivation for available action alternatives is high (cf. Fries et al., 2005; Riediger \& Freund, 2008).
Third, conflicting activities related to studying (i.e., study activities students did not pursue) are still characterized by a higher study motivation close to the exams.

Combining the first and second consideration, we predicted that the average intensity of motivational conflicts would be higher the closer an exam is in time. Taking into account the third consideration, we predicted that conflict situations in which the conflicting activity is study-related would be characterized by a higher conflict intensity. Likewise, we expected conflict situations in which students are not studying to be more intensive.

Finally, we reasoned that these effects would interact in the prediction of conflict intensity. We expected that conflicts would be particularly intense when students are not studying (main activity) but experienced a conflict concerning studying (conflicting activity). With regard to time, we expected motivational conflicts in which the conflicting activity is study-related to be more intense the closer the situation occurs to the exams. Likewise, we expected conflicts in which the main activity is not studying to be more intense the closer the exam is in time. From these considerations, we derive a set of six hypotheses, all of which predict under which circumstances the intensity of conflicts vary.

\section{Hypothesis Set 3: Motivational conflict intensity}

H3a The intensity of motivational conflicts is higher the closer an exam is in time (main effect time, regardless of activity context).

H3b The intensity of motivational conflicts is higher when the conflicting activity is study-related (main effect conflicting activity, regardless of time).

$\mathrm{H} 3 \mathrm{C}$ The intensity of motivational conflicts is higher when the main activity is not study-related (main effect main activity, regardless of time).

H3d The intensity of motivational conflicts is higher when the main activity is not study-related, and the conflicting activity is study-related (interaction between main activity and conflicting activity).

H3e The intensity of motivational conflicts is higher the closer an exam is in time when the conflicting activity is study-related (interaction between time and conflicting activity).

H3f The intensity of motivational conflicts is higher the closer an exam is in time when the main activity is not studyrelated (interaction between time and main activity). 


\section{Methods}

This study was approved by the Ethics Committee and Data protection office of the university where the study was conducted. Furthermore, the study conformed to all ethical standards of the German Psychological Association (DGPs).

\section{Sample and recruitment}

Overall, 138 first semester law students at a medium-sized university in Germany participated in the study. We had to exclude four participants from the analysis (see data preparation). The final sample consisted of 134 participants (70.3\% female) and a total of 4995 measurement points. All participants were in their first semester and the mean age of the final sample was $M_{\text {age }}=19.63(S D=1.61)$.

We recruited participants during lectures, introductory events for first semester students, and via an email distribution list of the faculty of law. Students interested in participating could enter their contact details in a list. We then contacted all students who qualified for participation until data collection capacities (i.e., the 100 available smartphones available for the purpose of the study) were reached. Data collection capacities were planned in order to ensure that the final sample exceeded current sample size recommendations for two-level hierarchical models (e.g., Curran et al., 2010; Maas \& Hox, 2005; Schoeneberger, 2016). In order to ensure a more balanced sample, we offered all male students to participate and recruited the remaining places randomly from the group of the remaining interested female participants. Participants received an expense allowance of $30 €$ if they answered less than $80 \%$ of the transmitted experience sampling signals and $50 €$ if they answered more than $80 \%$ of the signals.

\section{Procedure}

We used the experience sampling method (ESM) to assess students' activities and experience of motivational conflicts while exams came closer in time. ESM allows us to measure experience and behavior when it occurs and where it occurs, thus reducing biases that may be introduced by memory distortions or context effects during assessment in a laboratory (Trull \& Ebner-Priemer, 2014).

Participants took part in introductory meetings in small groups. A test supervisor informed participants about the purpose of the study and briefed them on the experience sampling procedure. Participants were given the opportunity to ask questions and subsequently filled in questionnaires regarding demographic data and the exams they planned on taking on a computer using the software questback unipark (EFS Survey 10.8). As this study was part of a larger data collection effort, other person-specific variables not relevant for the current study were also assessed.

100 participants were given a smartphone (Motorola Moto E) with the preinstalled experience sampling software (movisensXS Version 0.8.4208) and 39 students installed the software on their own smartphone. The experience sampling period started between one and five days after the introductory meeting and covered the same week for all students.

The ESM study took place two weeks before the end of the semester when exams typically take place at universities in Germany. We conducted data collection for all participants for one week right before exams took place. We hereby covered a period of time where exams were likely relevant for students' activities and their motivational conflict experience (e.g., Blasiman et al., 2017; Liborius et al., 2019). Participants independently completed questionnaires in their current everyday situation. For this purpose, the software on participants' mobile phones sent them six times a day within a $12 \mathrm{~h}$ time window (either from 8 a.m. to 8 p.m. or from 10 a.m. to 10 p.m.) a request to answer the ESM questionnaires (signal contingent design). The signals were sent quasi-randomly within predefined two-hour time windows, with a minimum interval of $30 \mathrm{~min}$ between signals. Signals were evaluated as not answered if a signal was either ignored for more than $15 \mathrm{~min}$ or shifted three times by $10 \mathrm{~min}$ ("snoozed"). The signal schedule and response data were stored locally on participants' devices to avoid any systematic missings due to radio holes. Overall compliance was very good with $88.95 \%$ of all signals answered.

Between 10 and 14 days after the ESM period, students were asked again to visit the work unit conducting the study. They filled in another computer-based questionnaire on person-specific data and their experience during the ESM assessment. They returned the study smartphone, were thanked by the experimenter, and received their compensation.

\section{Variables and measurements}

The data for this study were collected in the context of a larger project. Only measures that are relevant for the current study are described here. The complete list of measures can be obtained from the corresponding author. The data used will be made available in a public data archive for secondary analysis. ${ }^{1}$ None of the focal results reported here have been reported in any prior work. Note that the study was

\footnotetext{
1 The dataset is currently being archived with the Leibniz-Institute for the Social Sciences and is scheduled to be available after October 31st, 2021, in the Data Archive for the Social Sciences (DAS): https:// www.gesis.org/en/institute/departments/data-archive-for-the-socialsciences.
} 


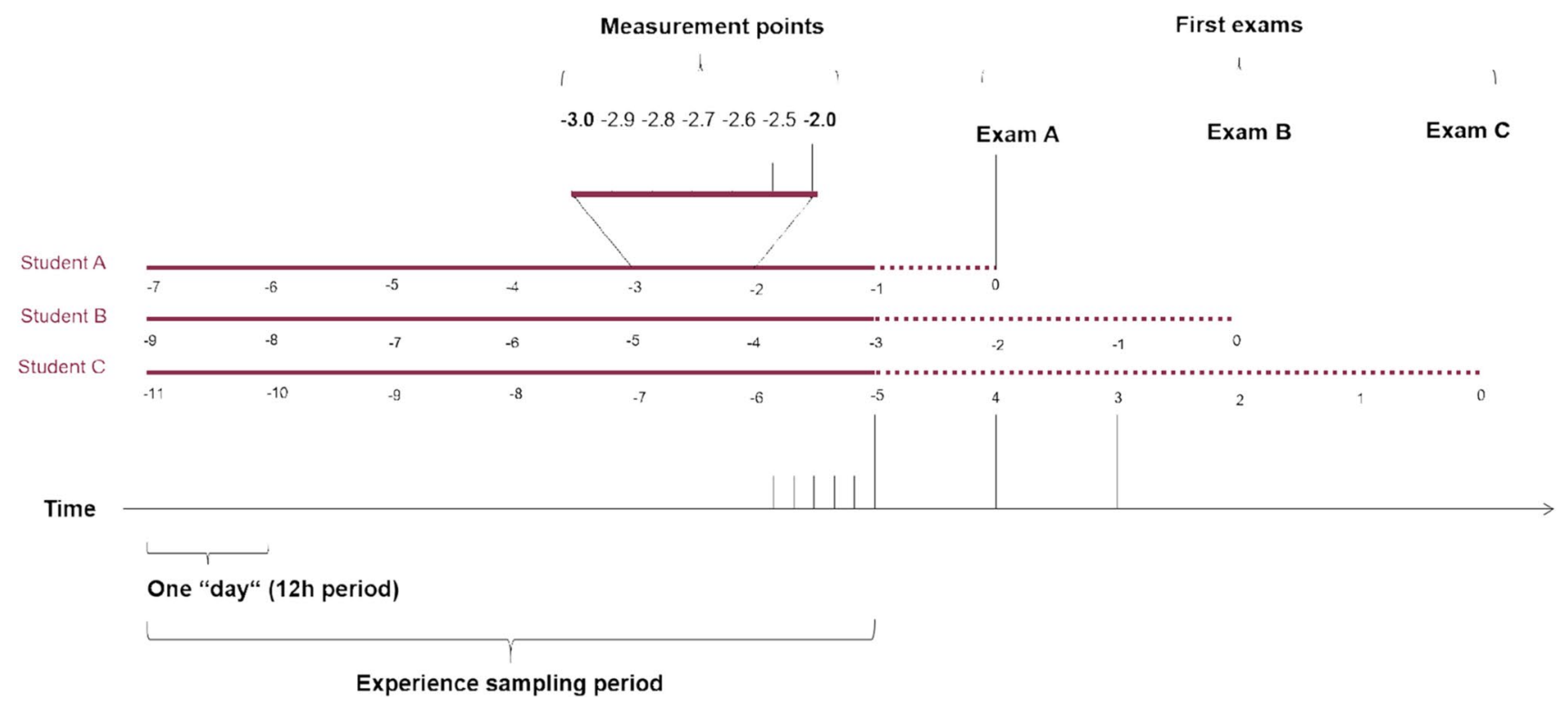

Fig. 1 Illustration of how time was coded using the example of three fictitious students with arbitrary distances to exams. The experience sampling period of seven days was the same for all students and started on a Saturday and ended on a Friday

conducted in German and all items presented in the manuscript have been translated into English.

\section{Experience sample measures}

All measures used in the main analysis of the present study are situational measures representing within-person changes between assessment situations.

\section{Exam date and time}

Students in Germany are usually free to decide which exams they want to take at the end of the semester. Therefore, even students from the same cohort can take different exams at different times. During the posttest, students indicated which exams they had taken. The corresponding date was set as zero point for each students' individual timeline (see exemplary students A, B, and C in Fig. 1). From this individual zero point, we counted the days back until the beginning of the experience sampling period which was the same for all students. Therefore, each students' individual time scale starts with a negative integer representing the number of days until their respective first exam (i.e., the zero point of the individual timeline). Within the experience sampling period, each day was again subdivided to account for the measurement points per day using the decimal places between two integers. For example, the second-last day before an exam is represented like this: $-2,-1.9,-1.8$, $-1.7,-1.6,-1.5$. Note that this string of integers ends with -1.5 . This was done to divide each day evenly between the twelve-hour ESM phase and the twelve-hour period until the beginning of the next day. The first signal of the last day before the exam was thus " -1 " (followed by $-0.9,-0.8$, etc.). This procedure is consistent with the approaches to coding time reported elsewhere (e.g., Kosovich et al., 2017).

\section{Main activity}

Students were asked "What was the main activity you were doing right before the alarm?" and could choose their answer out of five options: Studying, routines, commute, obligations, and leisure/entertainment. As we were interested in comparing study and non-study activities, we coded study activity as " 0 " and coded all non-study activities (i.e., leisure, routines, commute, obligations) as " 1 ".

\section{Motivational conflict experience (frequency and intensity)}

After they indicated their main activity, participants were asked "When the signal occurred, I felt that I wanted to or should do something else" and indicated the degree to which they agreed on a five-point scale ( $1=$ doesn't fit at all, 2, 3, 4, 5 = fits perfectly; cf. Riediger \& Freund, 2008). In order to distinguish conflict frequency and conflict intensity, we created two separate variables using this item. For conflict frequency, we created a dichotomous variable and coded everyone ("doesn't fit at all") on the above scale as "no conflict" (0) and any other response (i.e., two to four) as "conflict" (1). For conflict intensity, we used every number above one and subtracted one in order to gain a four-point scale to indicate the intensity of a motivational conflict from 1 to 4 . 


\section{Conflicting activity}

If participants indicated that they were experiencing a motivational conflict (i.e., gave an answer above 1 in the previous motivational conflict experience questionnaire), they were asked "What was the activity you wanted or should do rather than your main activity?" Analogous to the main activity, they could select their answer out of five options (studying, routines, commute, obligations, and leisure/entertainment). We again were interested in comparing study and non-study activities. We therefore coded study activity as " 0 " and coded all non-study activities (i.e., leisure, routines, commute, obligations) as " 1 ".

\section{Filler items}

Whenever participants reported that they were not experiencing a motivational conflict, they were asked additional questions not relevant to the current study. This was done in order to ensure that the experience sampling questionnaire was always the same length regardless of participants' response.

\section{Data preparation}

After data collection was concluded, pretest, ESM and posttest data sets were downloaded from their respective servers or smartphones and merged into a single data set using participants' unique identification codes using Microsoft Excel. The data was subsequently prepared for analysis using IBM SPSS version 24. During data preparation, four participants had to be excluded from further analysis. Two participants had not indicated an exam they planned to take, and two participants had to be excluded because they had not indicated any study activity during the survey period. For some students, the first exams attended already took place during the ESM data collection period and subsequent measurement points were also excluded from the analyses (160 in total). The final sample consisted of 4995 measurement points nested within 134 participants. Unless indicated otherwise, analyses refer to this final sample.

\section{Data analysis}

Data analysis for descriptive results and the creation of plots was done using IBM SPSS Version 24 and Microsoft Excel. Hypothesis testing was done using Mplus Version 8.2. In order to account for the hierarchical structure of the data, i.e., situations (Level 1) nested within persons (Level 2), we used multilevel modeling for all hypothesis tests. Descriptive results ignore the hierarchical data structure.

As we were mainly interested in the intra-individual changes over time (i.e., the situational changes within a "typical" student), we only used Level 1 predictor variables. Because we still expected differences in these effects between students, we allowed both individual intercepts and slopes to vary. The inclusion of these "random" intercepts and slopes gives an indication of the between-student variance around the estimated fixed effects (e.g., Geiser, 2011; Yarkoni, 2019).

We used multilevel logistic regression to test our first and second set of hypotheses because the criterion variables main activity and conflict frequency are dichotomous. We used multilevel regression analysis to test our third set of hypotheses because motivational conflict intensity is assumed to be scaled on an interval (cf. Riediger \& Freund, 2008). All analyses were done using the maximum likelihood estimator which is standard in Mplus. It is robust when assumptions of normal distributions are not met (e.g., Geiser, 2011; Muthén \& Muthén, 2017). Missing data was handled using the full information maximum likelihood approach (FIML) which is also standard in Mplus. We entered the predictor variables uncentered because we coded both categorical activity variables and time to have meaningful intercepts (e.g., Aiken et al., 1991; Nezlek, 2012). We also report unstandardized coefficient estimates and confidence intervals because they are readily interpretable in case of our analyses. In addition, there are currently no agreed-upon guidelines on how to report standardized effect sizes of multilevel logistic models with dummy-coded predictors (e.g., Lorah, 2018; Nezlek, 2012; Wang et al., 2019).

For each of the three criterion variables considered in the hypothesis sets, we started our analysis with an intercept only-model (null model) to assess the division of variance between the within-person (Level 1) and the between-person (Level 2) levels based on the intraclass-correlation (ICC). We then added predictor variables in order to account for the predicted main effects and considered the interaction effects in an additional model. The Level 1 fixed effects in the results tables thus represent the situational within-person effects of the predictors on the respective criterion variables and the Level 2 random effects represent the between-person variation of the fixed effects.

\section{Results}

\section{Descriptive frequency and progression of main activities, motivational conflicts, and conflict activities}

We recorded a total of 4995 situations during the experience sampling period. In 1715 (34.3\%) of these situations, students indicated that they were pursuing study activities and non-study activities in $3280(65.7 \%)$ of all situations. Non-study activities included "commute" in $427(8.5 \%)$ 
situations, leisure activities in 1298 (26.0\%) situations, routines in 1348 (27.0\%), and other obligations in 207 (4.1\%) situations. Overall, students indicated in 1428 of all situations (28.5\%) that they were experiencing a motivational conflict. Table 1 shows the absolute frequencies of conflicts between activities. Students experienced relatively few motivational conflicts while studying ( $18.5 \%$ of all study situations) compared to non-study activities (33.9\% of all non-study situations). The most frequent combination out of all conflict situations were situations in which students did not study but felt like they wanted to or should study (54.3\% of all conflict situations). Conflicts between study activities were relatively rare (7.8\% of all conflict situations). The average conflict intensity across all participants and situations was $M_{\text {intensity }}=2.66(S D=1.09, \min =1, \max =4)$.

\section{Probability of study activities}

Results are shown in Table 2. Intraclass correlation was .125 , indicating that $12.5 \%$ of the variance in the criterion variable can be attributed to differences between students (Level 2) while the remaining $87.5 \%$ can be attributed to situational differences within students (Level 1). H1 predicted

Table 1 Overview of the absolute and relative frequencies of conflict combinations (main activities vs. conflict activities)

\begin{tabular}{lccc}
\hline Conflicting activity & \multicolumn{3}{l}{ Main activity } \\
\cline { 2 - 4 } & Study & Nonstudy & Total \\
\hline Study & $111(2 \%)$ & $775(16 \%)$ & $886(18 \%)$ \\
Nonstudy & $206(4 \%)$ & $336(7 \%)$ & $542(11 \%)$ \\
No conflict & $1398(28 \%)$ & $2169(43 \%)$ & $3567(71 \%)$ \\
Total & $1715(34 \%)$ & $3280(66 \%)$ & $4995(100 \%)$ \\
\hline
\end{tabular}

Total number of situations: $\mathrm{N}=4995$ that study activities increased until the exam. In order to test this, we added time as the only predictor into the model (Table 2, Model 1). The criterion variable is the dummycoded main activity context. The fixed main effect for time indicates a statistically significant $(p<.001)$ decrease in non-study activities (coded 1) and thus an increase in study activities (coded 0 ) over time. The regression coefficient represents the change in the log odds of the outcome for a one unit increase in the predictor variable (Sommet \& Morselli, 2017). Expressed in probabilities, the model thus suggests that the probability of an average student to study increases by $13.9 \%(95 \%$ CI $10.1 \%, 17.8 \%)$ with each day the exam is closer in time. We therefore retain H1. Note that these results represent changes in probabilities and not the probability of study activities on a particular day. Instead, Fig. 2 illustrates the trajectory of the probability of studying for each day implied by the model: The probability of study activities within the assessed 12 -h periods was, on average, around $10 \%$ at the maximum temporal distance from the exam (13 days) and around 50\% at the day of the exam (cf. Figure 2). Level 2 random effects indicate that while there was substantial and statistically significant variation between students in model intercept but little variation between students in the change of study probability over time.

\section{Probability of motivational conflicts}

All results for our second set of hypotheses are shown in Table 3. Intraclass correlation was .315, indicating that most of the variance of conflict probability can be attributed to differences within students with substantial variation between students.

Table 2 Multilevel logistic regression of study activity frequency (likelihood) on time

\begin{tabular}{|c|c|c|c|c|c|c|c|c|c|c|}
\hline \multicolumn{11}{|l|}{ Main activity frequency } \\
\hline & \multicolumn{5}{|c|}{ Null model (intercept only) } & \multicolumn{5}{|c|}{ Model 1 (time only) } \\
\hline & $\mathrm{B}$ & SE & $95 \% \mathrm{CI}$ & OR & $95 \% \mathrm{CI}(\mathrm{OR})$ & $\mathrm{B}$ & SE & $95 \% \mathrm{CI}$ & OR & $95 \% \mathrm{CI}(\mathrm{OR})$ \\
\hline \multicolumn{11}{|l|}{ Fixed effects (Level 1) } \\
\hline Intercept (threshold) & $0.648 * * *$ & 0.058 & $\begin{array}{l}-0.762 \\
-0.535\end{array}$ & 1.912 & $\begin{array}{l}0.467 \\
0.586\end{array}$ & 0.064 & 0.101 & $\begin{array}{l}-0.133 \\
0.262\end{array}$ & 1.066 & $\begin{array}{l}0.875 \\
1.299\end{array}$ \\
\hline Time & & & & & & $-0.130^{* * *}$ & 0.017 & $\begin{array}{l}-0.163 \\
-0.096\end{array}$ & 0.878 & $\begin{array}{l}0.849 \\
0.908\end{array}$ \\
\hline \multicolumn{11}{|l|}{ Random effects (Level 2) } \\
\hline Intercept & & & & & & $0.506^{* *}$ & 0.150 & $\begin{array}{l}0.211 \\
0.801\end{array}$ & 1.659 & $\begin{array}{l}1.236 \\
2.226\end{array}$ \\
\hline Time & & & & & & 0.006 & 0.004 & $\begin{array}{l}-0.001 \\
0.013\end{array}$ & 1.006 & $\begin{array}{l}0.998 \\
1.014\end{array}$ \\
\hline
\end{tabular}

Dependent variable: main activity $(0=$ study. $1=$ non-study $)$

$* \mathrm{p}<.05, * * \mathrm{p}<.01, * * * \mathrm{p}<.001$ (two-tailed) 
Fig. 2 Progression of the average probability of study activities over the covered time period as predicted by Table 2 , Model 1. The model predicts an increase in the probability to study of $13.9 \%$ per day. $\mathrm{X}$-axis: Temporal distance from the exam in days $($ exam $=0)$. Y-axis: Probability to study

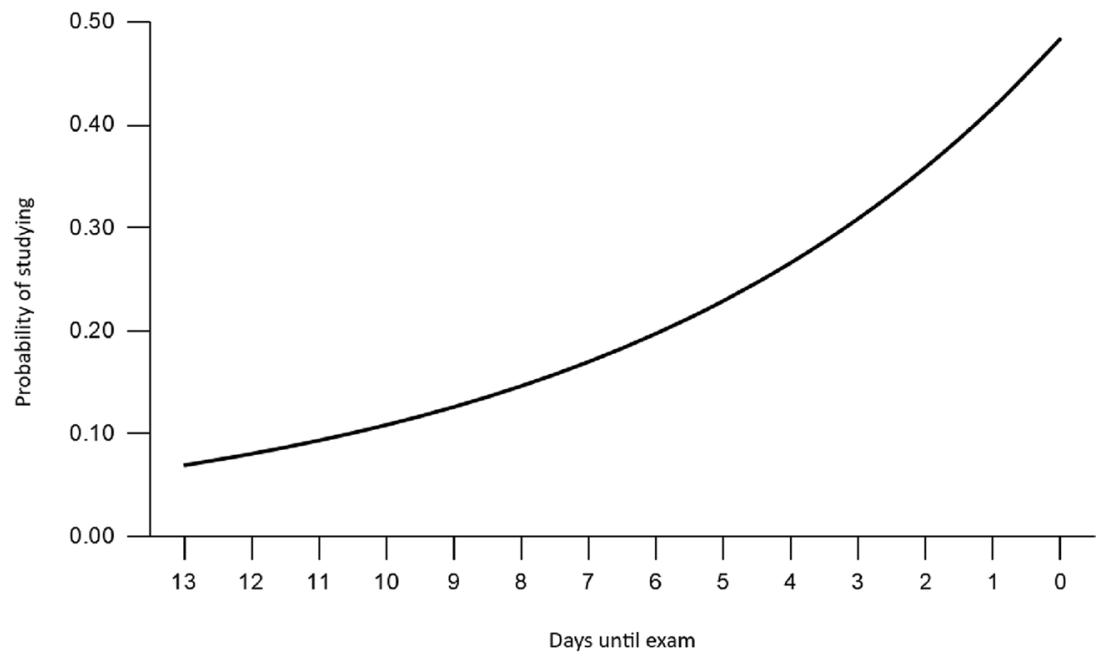

Hypothesis H2a predicts that the probability of motivational conflicts is lower the closer an exam is in time, regardless of the activity they pursued. In order to test this, we added time along with the main activity context into the model (Table 3, Model 1). The fixed main effect for time indicates a statistically significant $(p<.001)$ decrease in conflict frequency over time. The model implies that the probability of the average student to experience a motivational conflict decreases by $17.5 \%$ (95\% CI $11.7 \%, 23.5 \%$ ) with each day the exam is closer in time. We therefore retain H2a. Figure 3 again illustrates the progression of the probability of study activities as implied by the model: The probability to experience a motivational conflict 13 days before the exam was around $40 \%$ and only around 5\% at the day of the exam.

Hypothesis $\mathrm{H} 2 \mathrm{~b}$ predicts that the probability of motivational conflicts is lower for study activities compared to nonstudy activities over the entire sampling period. The fixed effect for main activity $(p<.001)$ indicates an increased conflict frequency if the main activity is not study-related as opposed to study-related (Table 3, Model 1). The model thus implies that a situation in which students are not studying is associated with an increased probability of $217.7 \%$ (95\% CI $132.1 \%, 335.9 \%)$ to experience a motivational conflict compared to a situation in which they are studying. We therefore retain $\mathrm{H} 2 \mathrm{~b}$.

Hypothesis $\mathrm{H} 2 \mathrm{c}$ predicts that the probability of motivational conflicts is lower for study activities (as opposed to non-study activities) the closer the exam is in time. We therefore added an interaction term between time and main activity into the model to test this prediction (Table 3, Model 2 ). Note that both the interpretation of the model intercept and the interpretation of the (now) conditional main effects change due to the introduction of the interaction term (e.g., Bauer \& Curran, 2005). The interaction term is statistically significant $(p=.009)$ with a relatively small point estimate but also a small confidence interval. We therefore concluded that the interaction between time and main activity is nonnegligible and plotted the interaction for interpretation (Fig. 4). The plot shows that the probability to experience a motivational conflict decreases for both main activity contexts over time but is consistently lower for the main activity "studying". Importantly, however, the probability appears to decrease more strongly for non-study activities. As H2c predicted an effect in the opposite direction, we reject it. Finally, note that Level 2 random effects indicate statistically significant and in part substantial variation between students regarding all of these results.

\section{Intensity of motivational conflicts}

All results for our third set of hypotheses are shown in Table 4. Because we only considered situations in which a motivational conflict occurred, the number of measurement points was reduced (i.e., 1428 situations nested in $130 \mathrm{stu}$ dents). The sample size on both levels could still be expected to yield accurate estimations of standard errors (Maas \& Hox, 2005; Paccagnella, 2011). ICC was .251, again indicating that most of the variance of conflict intensity can be attributed to differences within students with substantial variation between students.

Hypothesis H3a predicts that the intensity of motivational conflicts is higher the closer the exam is in time. The regression coefficient for the main effect of time is 0.035 (95\% CI $0.009,0.062 ; p=.009$ ). The model therefore implies that the average intensity of motivational conflicts increased on average from 2.405 on the conflict intensity scale at 13 days before the exam to 2.860 at the day of the exam (at the model intercept when time $=0$ ). This corresponds to almost half a point on the four-point conflict intensity scale for the point estimates. We judged the estimated effect of time on conflict intensity to be non-negligible and therefore retain H3a. 


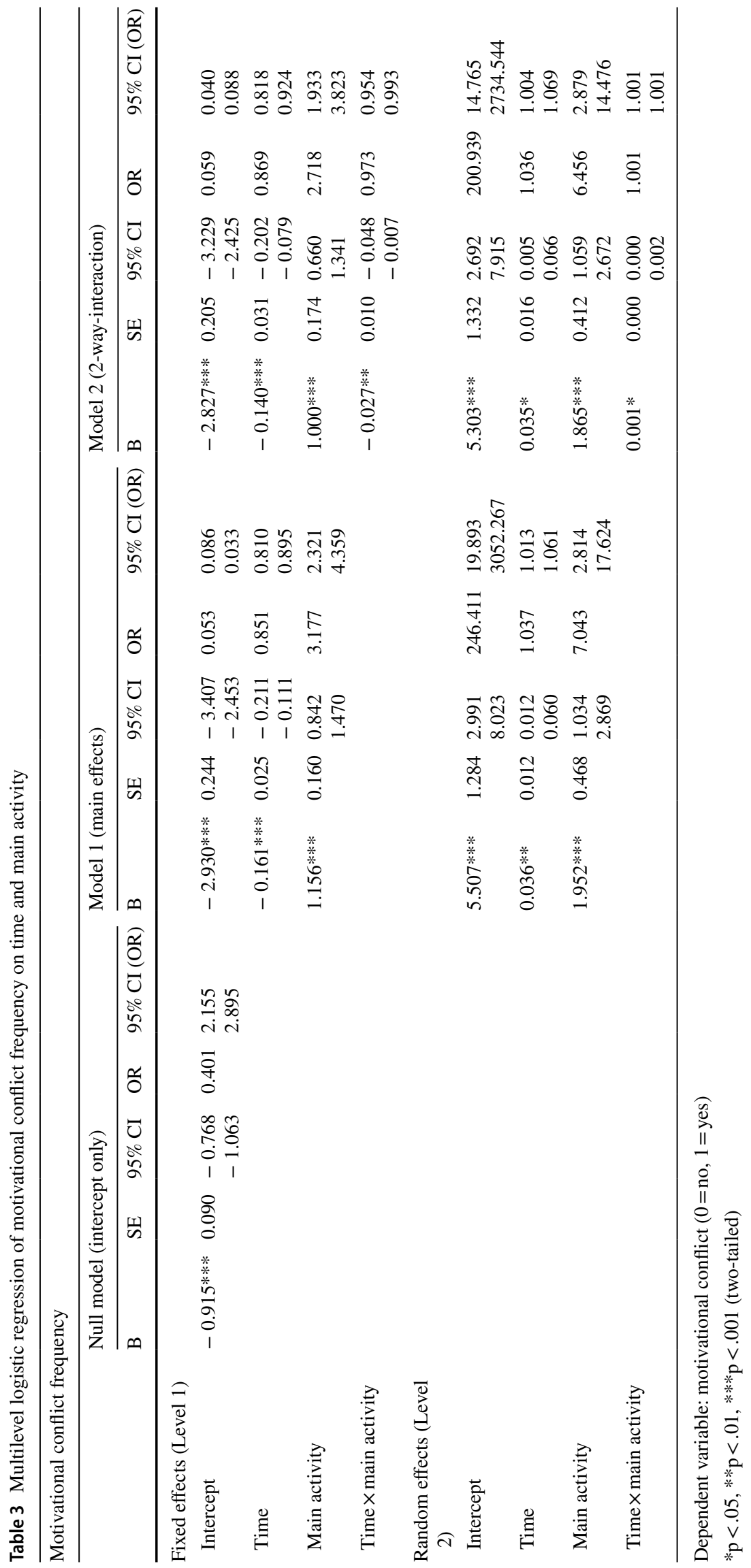


Fig. 3 Progression of the average probability of motivational conflicts over the covered time period and both activity contexts as predicted by Table 3 , Model 1 . The model predicts a decrease in the probability of motivational conflicts of $17.5 \%$ per day. X-axis: Temporal distance from the exam in days $($ exam $=0)$. Y-axis: Probability to experience a motivational conflict
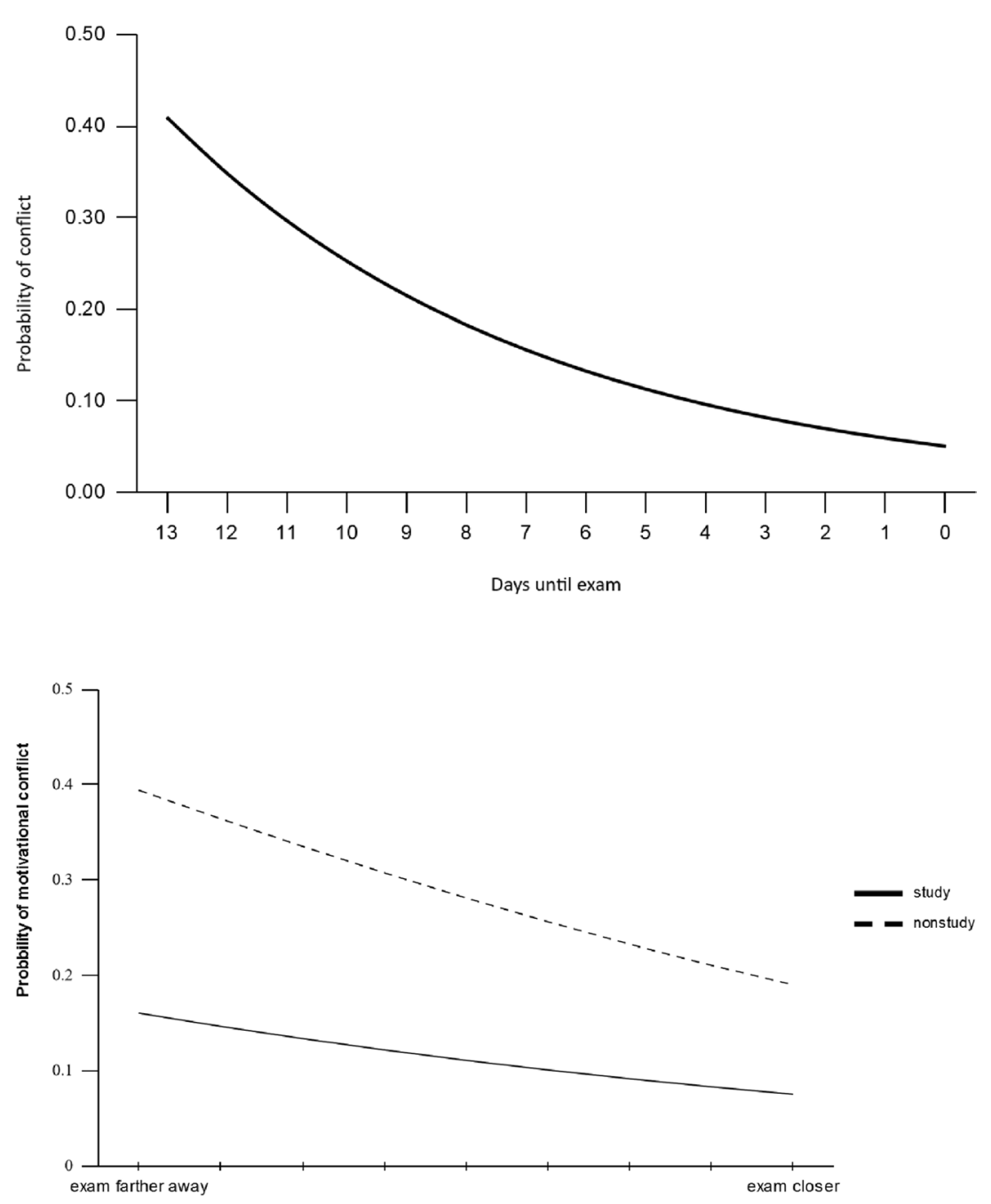

Fig. 4 Interaction effect between time and activity context in predicting the probability of a motivational conflict. $\mathrm{X}$-axis: Temporal distance from the exam. Y-axis: Probability to experience a motivational conflict
Hypothesis $\mathrm{H} 3 \mathrm{~b}$ predicts that the intensity of motivational conflicts is higher when the conflicting activity is study related. The corresponding coefficient was statistically significant $(p=.002)$. The point estimate and the $95 \%$ confidence interval suggest a slight increase of conflict intensity if the conflicting activity was study-related (as opposed to unrelated to studying). We thus retain $\mathrm{H} 3 \mathrm{~b}$.

$\mathrm{H} 3 \mathrm{c}$ predicts that the intensity of motivational conflicts is higher when the main activity is not study related. The corresponding regression coefficient was not statistically significant $(p=.411)$. Although the point estimate of the regression coefficient points towards a higher conflict intensity for activities that are not study related, the $95 \%$ confidence interval suggests that conflict intensity could also be higher for study activities. We thus reject $\mathrm{H} 3 \mathrm{c}$.

Hypotheses $\mathrm{H} 3 \mathrm{~d}$ and $\mathrm{H} 3 \mathrm{e}$ predict interactions between time and the main activity and between time and the conflicting activity, respectively. Hypothesis $\mathrm{H} 3 \mathrm{f}$ predicts an interaction between main activity and conflicting activity. We added these interaction terms all at once to the model (Table 4, Model 2). The interactions between time and activity context (studying vs. non-studying) were not statistically significant ( $p=.872$ for time $\mathrm{x}$ main activity and $p=.802$ for time $\mathrm{x}$ conflicting activity) and yielded small point estimates for the regression coefficients with large $95 \%$ confidence intervals. We thus reject $\mathrm{H} 3 \mathrm{~d}$ and $\mathrm{H} 3 \mathrm{e}$.

The interaction between main and conflicting activity was statistically significant $(p=.049)$ with a comparatively large coefficient estimate. We thus plotted the interaction for interpretation (Fig. 5). The plot showed that the average conflict intensity was very similar for both conflicting activity contexts if students were pursuing study-related activities. In contrast, conflict intensity was higher when students pursued an activity unrelated to studying but experienced a conflict with regard to a study-related activity (as opposed to a conflict regarding an activity that was not study-related). As we predicted that both main and conflicting activity would contribute to the intensity of motivational conflicts, we reject H3f. Finally, note that the random effects indicate statistically significant variation between students regarding model intercepts and for the main effect of time but not for the other effects. 
Table 4 Multilevel regression of motivational conflict intensity on time, main activity, and conflicting activity

Motivational conflict intensity

\begin{tabular}{|c|c|c|c|c|c|c|c|c|c|}
\hline & \multicolumn{3}{|c|}{ Null model (intercept only) } & \multicolumn{3}{|c|}{ Model 1 (main effects) } & \multicolumn{3}{|c|}{ Model 2 (2-way-interaction) } \\
\hline & $\mathrm{B}$ & SE & $95 \% \mathrm{CI}$ & B & SE & $95 \% \mathrm{CI}$ & $\mathrm{B}$ & SE & $95 \% \mathrm{CI}$ \\
\hline \multicolumn{10}{|l|}{ Fixed effects } \\
\hline Intercept & 2.618 & 0.055 & $\begin{array}{l}2.511 \\
2.726\end{array}$ & $2.860 * * *$ & 0.125 & $\begin{array}{l}2.615 \\
3.104\end{array}$ & $2.646 * * *$ & 0.181 & $\begin{array}{l}2.291 \\
3.001\end{array}$ \\
\hline Time & & & & $0.035 * *$ & 0.014 & $\begin{array}{l}0.009 \\
0.062\end{array}$ & 0.028 & 0.028 & $\begin{array}{l}-0.026 \\
0.082\end{array}$ \\
\hline Main activity & & & & 0.065 & 0.079 & $\begin{array}{l}-0.090 \\
0.219\end{array}$ & 0.281 & 0.177 & $\begin{array}{l}-0.065 \\
0.628\end{array}$ \\
\hline Confl. activity & & & & $-0.214 * *$ & 0.068 & $\begin{array}{l}-0.347 \\
-0.081\end{array}$ & 0.066 & 0.166 & $\begin{array}{l}-0.260 \\
0.392\end{array}$ \\
\hline Time $\times$ main activity & & & & & & & 0.004 & 0.026 & $\begin{array}{l}-0.047 \\
0.055\end{array}$ \\
\hline Time $\times$ confl. activity & & & & & & & 0.006 & 0.022 & $\begin{array}{l}-0.038 \\
0.049\end{array}$ \\
\hline Main activity $\times$ confl. activity & & & & & & & $-0.312 *$ & 0.159 & $\begin{array}{l}-0.622 \\
-0.001\end{array}$ \\
\hline \multicolumn{10}{|l|}{ Random effects } \\
\hline \multicolumn{10}{|l|}{ Level 1 (variances) } \\
\hline Residual & 0.858 & 0.050 & $\begin{array}{l}0.760 \\
0.956\end{array}$ & $0.792 * * *$ & 0.052 & $\begin{array}{l}0.690 \\
0.894\end{array}$ & $0.782 * * *$ & 0.053 & $\begin{array}{l}0.678 \\
0.885\end{array}$ \\
\hline \multicolumn{10}{|l|}{ Level 2 (variances) } \\
\hline Intercept & 0.287 & 0.040 & $\begin{array}{l}0.209 \\
0.365\end{array}$ & $0.693 * * *$ & 0.160 & $\begin{array}{l}0.379 \\
1.007\end{array}$ & $0.570 *$ & 0.226 & $\begin{array}{l}0.126 \\
1.013\end{array}$ \\
\hline Time & & & & $0.006^{*}$ & 0.003 & $\begin{array}{l}0.001 \\
0.011\end{array}$ & 0.005 & 0.002 & $\begin{array}{l}0.000 \\
0.010\end{array}$ \\
\hline Main activity & & & & 0.105 & 0.126 & $\begin{array}{l}-0.143 \\
0.353\end{array}$ & 0.049 & 0.166 & $\begin{array}{l}-0.277 \\
0.375\end{array}$ \\
\hline Conflicting activity & & & & 0.056 & 0.072 & $\begin{array}{l}-0.086 \\
0.197\end{array}$ & 0.024 & 0.133 & $\begin{array}{l}-0.235 \\
0.284\end{array}$ \\
\hline Time $\times$ main activity & & & & & & & 0.001 & 0.002 & $\begin{array}{l}-0.002 \\
0.005\end{array}$ \\
\hline Time $\times$ confl. activity & & & & & & & 0.000 & 0.002 & $\begin{array}{l}-0.003 \\
0.004\end{array}$ \\
\hline Main activity $\times$ confl. activity & & & & & & & 0.081 & 0.133 & $\begin{array}{l}-0.179 \\
0.340\end{array}$ \\
\hline
\end{tabular}

Dependent variable: conflict intensity, given a motivational conflict $(1=$ lowest to $4=$ highest $)$

$* \mathrm{p}<.05, * * \mathrm{p}<.01, * * * \mathrm{p}<.001$ (two-tailed)

\section{Discussion}

\section{Interpretation of key findings}

We investigated students' experience of motivational conflicts in the context of approaching exams as well as different activity contexts. Based on the temporal and multiple goals perspectives on study motivation, we assumed that an upcoming exam would be associated with asymmetric effects on students' study motivation relative to other activities. We further assumed that these effects would be indicated by a higher probability of study activities, a lower probability of motivational conflicts, and more intense motivational conflicts the closer the exam was in time. Our results largely support this assumption.

\section{Probability of study activities}

The closer the exam came, the more likely students were to spend their time studying. This finding supports the assumption of increasing relative study motivation and is in line with previous research on the distribution of study activities close to exams or deadlines (e.g., Ariely \& Wertenbroch, 2002; Dewitte \& Schouwenburg, 2002; Gjesme, 1975; 
Fig. 5 Interaction effect between main activity and conflicting activity in predicting conflict intensity. X-axis: Main activity context. Y-axis: Conflict intensity scale

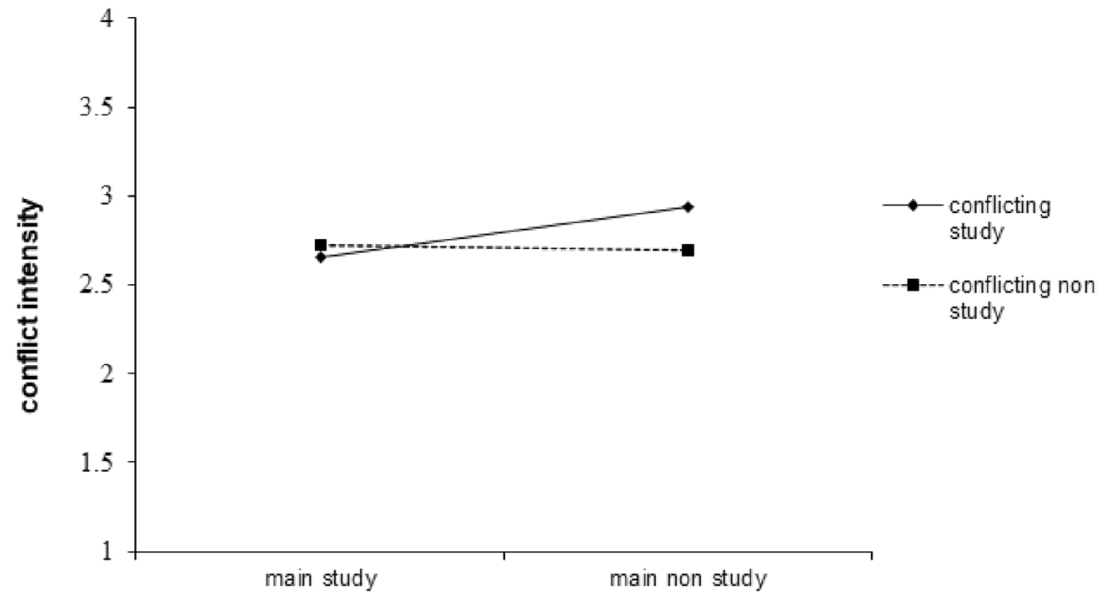

Howell et al., 2006; König \& Kleinmann, 2005; Taraban et al., 1999).

\section{Probability of motivational conflicts}

The closer the exam came, the less likely students were to experience motivational conflicts, regardless of their main activity (i.e., study or non-study activities). This finding is also in line with our assumption that while students would study more due to their increased study motivation, they would also actively choose what to do close to the exam and thus experience fewer conflicts even when they were not studying, thus resulting in less frequent conflicts (Hofer \& Fries, 2016).

While conflicts remained less likely during studying throughout the period covered, the conflict probability decreased more over time when students pursued non-study activities rather than study activities, which was contrary to our predictions (Fig. 4). In line with our reasoning that students actively choose what activities they engage in shortly before the exams, one explanation might be that students increasingly engage in non-study activities that are compatible with exam preparation, such as increasing inner focus through yoga or calming their nerves by watching a movie, thereby engaging in activities which are not studying but still compatible with the aim of optimal exam preparation. Alternatively, students might only engage in non-study activities that fulfill very important needs even before an exam. A third explanation might be that students experienced fewer motivational conflicts because they increased their study activities, which are generally associated with fewer conflicts close to an exam. To test these explanations, further studies are needed.

\section{Intensity of motivational conflicts}

The closer the exam came, students experienced the motivational conflicts that still occurred as more intense. Conflicts were also more intense when the conflicting activity was study-related (Fig. 5). Unexpectedly, however, the pursued main activity did not predict conflict intensity. Likewise, we found no evidence that the change in conflict intensity over time differed between activity contexts. While we rejected some of our hypotheses (i.e., H3c-f), these results are still largely compatible with our assumption that mainly conflicts between activities with a high motivation remain as the exam come closer. One explanation for our results might be that conflicts tend to be more intense the closer they arise to the exam as long as one of the action alternatives is studyrelated and thus characterized by an increased study motivation due to the upcoming exam. This was the case in $76.5 \%$ of all conflicts documented in our study (cf. Table 1). Any conflict that still occurs would then likely involve students' most important needs conflicting with the desire to prepare for the exam.

\section{Theoretical consequences}

Both the temporal perspective and the multiple goals perspective individually provide unique and potentially helpful perspectives on students' in-the-moment study motivation and its change between situations. Additionally, both perspectives can contribute to each other while their combination highlights the relevance of situational aspects of study motivation. At the same time, the question arises to what extent these situational aspects affect students equally or differently and which factors can account for potential betweenperson differences. We discuss all of these points below. 


\section{Temporal perspective}

The temporal perspective suggests that motivation for an activity can be conceived as relative to a relevant temporal landmark rather than only needs or goals that are relatively stable over time. Specifically, study motivation and study activities should generally increase as an exam approaches (e.g., Ainslie, 2010; Steel \& König, 2006; Trope \& Liberman, 2010). As we have already pointed out, the increases in study activities as indirect measures of study motivation we found in the current research is in line with previous findings, indicating a robust phenomenon (e.g., Howell et al., 2006; Taraban et al., 1999). The case is less clear with regard to directly measured motivation, however. The development of motivational beliefs over time has been considered before (Dresel \& Grassinger, 2013; Kosovich et al., 2017; Robinson et al., 2019; Wigfield \& Cambria, 2010). Still, this research has focused on the development of more general motivational orientations over longer time periods (i.e., one semester or more) rather than the development of in-the-moment with regard to temporal landmarks (Dietrich et al., 2017, 2019) and over short time periods (i.e., days or even hours; Kosovich et al., 2017). Interestingly, these studies have generally found decreases in study motivation over time. We address both this apparent contradiction and the probable nature of motivational changes over time below. As a preliminary point, it is worth noting that our findings highlight the general relevance of time as a situational factor in research on study motivation (Eccles \& Wigfield, 2020; Trope \& Liberman, 2010). Moreover, the distance of temporal landmarks as a predictor variable for motivation and behavior is methodologically attractive because it can be measured unambiguously on an interval scale and is a truly independent variable in that reverse causation from a psychological criterion variable on time can be excluded.

\section{Multiple goals perspective}

The multiple goals perspective suggests that motivation for an activity can be conceived as relative to other potential activities and goals rather than limited to one focal activity. Specifically, students are assumed to pursue study activities when their in-the-moment study motivation is higher than the current motivation for other available action alternatives (Hofer \& Fries, 2016; see also Atkinson, 1981). While some theories on study motivation consider alternative actions either implicitly (e.g., Heckhausen \& Gollwitzer, 1987) or explicitly either as opportunity costs (e.g., Flake et al., 2015; Kurzban et al., 2013) or as distracting temptation (e.g., Schouwenburg \& Groenewoud, 2001), the motivation for a focal study activity or studying in general is mostly at the center of research on student motivation (Hofer \& Fries, 2016). The multiple goals perspective takes a more holistic view of students by explicitly considering the role of action alternatives in study motivation. Assuming that students generally try to balance the attainment of different goals related to different needs (Dweck, 2017) implies that pursuing different activities than studying is not necessarily attributable to motivational deficiencies or avoidance behavior (e.g., Ferrari \& Tice, 2000; Ferrari et al., 1995; Vallerand et al., 1992). Rather, students may be more motivated to pursue a different activity, even before an exam (Hofer \& Fries, 2016). At the same, activities that were omitted in favor of a study activity may still be mentally present and can interfere with studying (Hofer \& Fries, 2016). Conversely, omitted study activities may interfere with activities that are not study related. Again, as a preliminary point, it can thus be noted that research on motivation regulation might profit from a stronger focus on achieving a balance between different goals or dealing with motivational conflicts rather than focusing exclusively on regulating the motivation for study activities, even close to exams (Hofer \& Fries, 2016; Wolters \& Rosenthal, 2000). Furthermore, it would be interesting to directly measure relative motivation for different action alternatives and their change between situations more directly. We are not aware of current instruments that would measure relative motivation in a specific situation.

\section{How can the temporal and the multiple goals perspectives benefit from one another?}

In addition to their individual contributions to the study of student motivation, both perspectives can benefit from one another. From a multiple goals perspective, temporal landmarks such as exams appear relevant for the experience of motivational conflicts. Students' conflicts are therefore likely not evenly distributed throughout a semester. Indeed, the overall proportion of conflict situations in our sample (Table 1) is smaller than was found in previous experience sampling studies on motivational conflicts that were conducted earlier in the semester (Grund et al., 2015). This could in turn mean that the effectiveness of self-regulation strategies to attain multiple goals (Hofer \& Fries, 2016) differs throughout a semester. Moreover, future research could investigate if other landmarks such as events in students' personal lives are also relevant for students' conflict experience and in particular motivational interference.

From a temporal perspective, multiple goals might help to explain the aforementioned apparent contradiction between increasing study activities and decreasing study motivation over time if methodological differences cannot account for the findings (Dresel \& Grassinger, 2013; Howell et al., 2006; Kosovich et al., 2017; Steel \& König, 2006). It seems possible, for example, that students' in-the-moment study motivation remains higher relative to available action alternatives even if absolute measurements of study motivation decrease 
over time (Atkinson, 1981; Hofer \& Fries, 2016). Indeed, it is conceivable that the mental presence of study activities increasingly interferes with students' non-study activities, decreasing their relative attractiveness close to exams.

\section{How much does the situation matter for study motivation?}

More broadly, our findings highlight the relevance of situational factors that determine study motivation and thus its variation within a person between situations (Brassler et al., 2016; Eccles \& Wigfield, 2020): The distance of a temporal landmark (i.e., an exam) is associated with systematic changes in the latent motivation for an activity related to the landmark (i.e., studying) relative to action alternatives unrelated to the landmark, as indicated by an increasing probability of study activities, a decreasing probability of motivational conflicts, and an increase in conflict intensity. However, an obvious corollary is: How much does the situation matter for study motivation?

Most motivation researchers would likely agree that study motivation is the result of an interaction between a person's relatively stable characteristics such as needs, values, goals, and skills and a situation such as task characteristics and available action alternatives (Dweck, 2017; Eccles \& Wigfield, 2020; Furr \& Funder, 2018; Heckhausen, 2020; Hofer $\&$ Fries, 2016). The same situation can thus generally be expected to elicit varying responses from different people based on their characteristics. However, the degree of variation between people in a situation might be lower in some cases: "To the extent that a given situation has powerful cues that activate particular beliefs, emotions, and action tendencies, it should trigger similar goals and similar behavior in many people" (Dweck, 2017, p. 705). Such situations with lower between-person variation have been called strong situations as opposed to weak situations which are characterized by higher between-person variation (Dweck, 2017; Fleeson, 2007; Mischel, 1977). The between-person variation (Level 2 random effects) of our within-person results (Level 1 fixed effects) can be seen as a first indicator for the "situational strength" of the variables considered in the current research (Yarkoni, 2019). Recall that we found relatively little, statistically non-significant variation between students regarding the increase of study activities over time (Table 2), indicating that most students increased their study activities as exams approached, regardless of their individual differences (Dewitte \& Schouwenburg, 2002; Howell et al., 2006; König \& Kleinmann, 2005; Taraban et al., 1999). However, we found substantial and statistically significant variation between students for estimated coefficients of the frequency of motivational conflicts (Table 3) and statistically significant between-person variation for the main effect of time on conflict intensity (Table 4), indicating that the changes of conflict experience over time and activities differed between students. The approaching exams thus appears to be a strong situation in the sense that the increasing study tendency holds for most students before exams. Still, upcoming exams (and the different activity contexts) are weak situations in that their association with conflict frequency and intensity is more varied between students. While part of this variation can likely be attributed to random events in students' lives during the sampling period such as other important life events or goals conflicting with exam preparation, it also hints at different qualities of in-the-motivation underlying students' increasing study activities before exams.

\section{What is the nature of increasing study motivation over time?}

While we treat in-the-moment study motivation as a latent variable that increases as exams approach for the purpose of our study, it seems interesting to speculate on its nature in light of our main (within-person) findings and their (between-person) variation. As previously mentioned, we conceptualized in-the-moment motivation for a specific activity in the sense of established theories such as situated expectancy value theory (e.g., Dietrich et al., 2017; Eccles \& Wigfield, 2020; Wigfield \& Eccles, 2000) or achievement goal theory (e.g., Elliot, 2006; Elliot \& Covington, 2001). According to Grund (2013), the aforementioned theories on study motivation brodaly distinguish between "the quantity of motivation (i.e., how much students are motivated)" and "the quality of motivation (i.e., why students learn)" (p. 202). The quality of motivation can again be broadly distinguished into more beneficial and more detrimental forms of motivation (e.g., Grund \& Fries, 2012). More beneficial motivation refers to situations in which individuals pursue an activity out of enjoyment or in order to reach a self-determined goal (e.g., intrinsic values or approach motivation; Eccles, 1983; Feltman \& Elliot, 2012). In contrast, more detrimental motivation includes situations in which individuals pursue an activity in order to reach a purely instrumental goal, to relieve internal or external pressure, or to avoid negative consequences (e.g., utility value, introjected or external motivation, or avoidance motivation; Deci \& Ryan, 2012; Eccles, 1983; Feltman \& Elliot, 2012; Hofer \& Fries, 2016). More detrimental forms of motivation for action alternatives are associated with more motivational interference (Grund, 2013; Grund et al., 2015; Hofer \& Fries, 2016).

As exams are externally imposed on students, they seem generally more likely to increase detrimental forms of motivation in most students by undermining more beneficial study motivation due to an overjustification or corruption effect (Amabile et al., 1976; Burgess et al., 2004; Deci, 1971; Tang \& Hall, 1995). In fact, students tend to switch to more superficial learning strategies toward the end of the semester which can be seen as an indicator for more detrimental study 
motivation (e.g., Deci, 1971; Naujoks \& Händel, 2020; Vansteenkiste et al., 2005). According to this line of thought, the increased probability of study activities we observed would be driven by more detrimental forms of motivation, which seems compatible with the notion of "cramming" before exams (e.g., Howell et al., 2006; Taraban et al., 1999). This speculation is also compatible with our findings regarding increased conflict intensity, as we would expect conflicts between more detrimentally motivated action alternatives to be more intense (Brassler et al., 2016; Grund \& Fries, 2012; Hofer \& Fries, 2016). In contrast, the assumption of increasing detrimental forms of study motivation seems difficult to reconcile with the decreasing probability of motivational conflicts during study activities and over time, as we would rather expect more frequent conflicts (e.g., Grund, 2013). One possible explanation would be that motivation quantity "trumped" motivation quality right before exams and thus prevented motivational conflicts from arising.

Furthermore, it seems possible that different kinds of "motivation" not typically considered in theories of study motivation underlie the effects we observed. For example, students' study activities could simply be motivated by fear of failing the upcoming exam (e.g., Beery, 1975; Cardetti \& McKenna, 2011). Indeed, Rottweiler et al. (2018) found that exam-related anxiety increases as an exam approaches. Alternatively, students might perceive the exam as an inevitable event by which they are passively "pulled" towards study activities (Trope \& Liberman, 2010). In both cases, it seems likely that students study more and lose sight of their other wants and shoulds, which would be broadly compatible with our findings. While these effects would still be considered motivation in its broadest sense (e.g., "any internal process that energizes, directs, and sustains behavior." Reeve, 2016, p. 31f), they seem less likely to be reflected in the motivational characteristics that play a central role in the aforementioned theories on study motivation (e.g., Eccles \& Wigfield, 2020; Pintrich, 2000).

However, considering the between-person variance regarding the findings on both conflict frequency and conflict intensity, it seems likely that these arguments do not apply to all students equally. Rather, the quality and quantity of increasing in-the-moment study motivation (Eccles \& Wigfield, 2020; Grund, 2013; Pintrich, 2000)—and potentially other kinds of motivation-before exams are likely to differ between students depending on students' characteristics and the characteristics of a particular exam (Dietrich et al., 2019; Trope \& Liberman, 2003). Differences in the nature of study motivation before an exam are still compatible with a relatively universal increase in study activities but could account for varying degrees of decreasing conflict probabilities and increasing motivation intensity, as students whose study activities are driven by more detrimental forms of motivation might still experience more frequent and intense conflicts (Brassler et al., 2016; Grund et al., 2015; Hofer \& Fries, 2016).

\section{Between-person differences and exam characteristics}

Several trait-level student characteristics are likely moderators that could explain the between-person variation of our findings and, presumably, differences in the quantity and quality of increasing study motivation before exams. In addition, instructors' presentation of exam characteristics is a likely moderator of study motivation both within and between persons.

On the student level, differences in personal goal orientations between students are likely to explain variation between students, as we would expect students with different goal orientations to perceive different motivational characteristics of an upcoming exam more readily (Kaplan \& Maehr, 2007; Wolters, 2004). Likewise, differences in future time perspective between students are likely to explain between-person variation because the psychological distance and the utility of future goals is perceived differently (Lewis \& Oyserman, 2015; Simons et al., 2004). Finally, differences in trait self-control are likely to account for between-student differences, as students with high trait self-control are more likely to adaptively prevent and deal with conflicts between action tendencies (De Ridder et al., 2012; Fujita, 2011; Hofmann et al., 2009).

While we argued that exams are imposed on students and thus generally more likely to induce less beneficial forms of study motivation, the exact exam characteristics, and the way they are communicated are likely to differentially affect the quality of students' study motivation. In addition to the content, structure (Belenky \& Nokes-Malach, 2013) and difficulty of an exam (Britt, 2005), instructors' communication or "framing" of an exam is likely to affect students' study motivation before exams (Bies-Hernandez, 2012; Trope \& Liberman, 2010; Vansteenkiste et al., 2005, 2008; Wolters, 2004). For example, instructors can frame an exam either as an opportunity for students to demonstrate their knowledge or as a test whose failure has negative consequences, thus highlighting different motivational characteristics of the exam. We assume that framing exams as opportunity is likely to be associated with more beneficial forms of study motivation while framing an exam as a test with potential negative consequences is more likely to induce detrimental forms of study motivation, regardless of individual differences between students (Belenky \& Nokes-Malach, 2013; Putwain \& Remedios, 2014; Vansteenkiste et al., 2008), although there is some evidence of differential task framing effects for less extreme examples (Canning et al., 2019). Note that differences in exam characteristics would explain some of the between-student variation in the trajectories of motivational variables over time in our sample, as students 
attended different exams. However, if a student takes multiple exams, these exams could be considered situational within-person predictors of study motivation.

\section{Potential practical implications}

While the present research is correlational in nature, it still provides some pointers at potential practical implications. Bjørnebekk and Gjesme (2009) state that "educators commonly use temporal distance to a goal as a motivational strategy" (p. 339), for example by giving students deadlines throughout the semester rather than one (or several) only at the end of the semester. Even just the perception of the distance of temporal landmarks can be manipulated in order to increase study motivation (Peetz et al., 2009). Our findings hint at the possibility that manipulations of the temporal distance of goals (real or perceived) might not only increase study motivation but may also reduce the frequency of motivational conflicts. However, our findings also suggest that such interventions can potentially come at the cost of increased conflict intensity and superficial learning (Deci, 1971; Naujoks \& Händel, 2020; Vansteenkiste et al., 2005). A more robust approach to enhancing students' study motivation while minimizing the probability of motivational conflicts might be framing an exam in a way that encourages beneficial forms of study motivation (e.g., Jackson, 2002), which would also help to further reduce the frequency and intensity of motivational conflicts before exams (Hofer \& Fries, 2016).

\section{Limitations}

Our study has a number of limitations that need to be addressed to contextualize our findings. First, the present research is correlational in nature aimed at establishing a first empirical connection between two perspectives on student motivation and does not warrant causal conclusions.

Secondly, our sample consisted of considerably more female than male participants and only first-semester law students. As of now, it is unclear if our findings generalize to other groups. Second, because random recruitment from our target population was not possible, it is possible that our sample is somewhat biased. For example, students who expected to get well through the exam period might have been more willing to participate in an experience sampling study. While we expect the comparatively high incentives for participation in our study to offset such effects to some degree, we cannot rule them out. Third, we assessed our sample during one full week just before exams using the experience sampling method. It is therefore unclear if our findings generalize to other time periods or other types of testing. While the coding of individual timelines should control for the effect of particular weekdays and previous research did not find statistically significant effects of weekdays on study activities (e.g., Liborius et al., 2019) or on the experience of motivational conflicts (e.g., Riediger $\&$ Freund, 2008), this possibility cannot be ruled out in our sample. Finally, although our ESM surveys were balanced using filler items, it is still possible that the decrease in motivational conflict probability we measured was at least in part due to some measurement bias.

\section{Conclusion}

In the present study, we investigated if students' study activities and their experience of motivational conflicts (i.e., their frequency and intensity) changed when exams come closer in time. Using the experience sampling method, we assessed students' activities and conflict experience in their everyday lives immediately before an upcoming exam. In doing so, we attempted to empirically connect two distinct perspectives on study motivation: (i) the temporal perspective which stresses the importance of a temporal landmark (i.e., an exam) related to an activity (i.e., studying) and (ii) the multiple goals perspective which stresses the importance of relative motivation for available action alternatives (i.e., studying or pursuing a non-study activity) and the possibility of conflicts between these activities. The unifying factor of these two perspectives is that they consider the situated nature of study motivation by addressing situational factors related to students' in-the-moment motivation. We assumed that study motivation increases relative to the motivation for other activities in students' lives and that this increase would be mirrored by increasing study activities, a decreasing conflict probability, and an increased intensity of the remaining conflicts as exams approach. In addition, we assumed that students' situational conflict experience would depend on whether they are either actually or mentally engaged with studying (i.e., the current activity context). Our results show that study activities, conflict probability, and conflict intensity develop as predicted. While we could not retain all of our hypotheses with regard to activity contexts, our results are largely compatible with the assumption that relative study motivation increases before exams. We are encouraged by our findings to further examine the exact nature of relative in-the-moment study motivation and its situational and person-specific determinants.

Funding Open Access funding enabled and organized by Projekt DEAL. The study was funded by a research grant by the German 
Federal Ministry of Education and Research (BMBF), Grant Number 01PB14003A.

\section{Declarations}

Conflict of interest The authors declare no conflicts of interest.

Ethical approval This study was approved by the Ethics Committee and Data protection office of Bielefeld University where the study was conducted. The study conformed to all ethical standards of the German Psychological Association (DGPs).

Open Access This article is licensed under a Creative Commons Attribution 4.0 International License, which permits use, sharing, adaptation, distribution and reproduction in any medium or format, as long as you give appropriate credit to the original author(s) and the source, provide a link to the Creative Commons licence, and indicate if changes were made. The images or other third party material in this article are included in the article's Creative Commons licence, unless indicated otherwise in a credit line to the material. If material is not included in the article's Creative Commons licence and your intended use is not permitted by statutory regulation or exceeds the permitted use, you will need to obtain permission directly from the copyright holder. To view a copy of this licence, visit http://creativecommons.org/licenses/by/4.0/.

\section{References}

Aiken, L. S., West, S. G., \& Reno, R. R. (1991). Multiple regression: Testing and interpreting interactions. Sage.

Ainslie, G. (2010). Picoeconomics: The strategic interaction of successive motivational states within the person (1 paperback ed., paperback re-issue). Studies in rationality and social change. Cambridge University Press.

Amabile, T. M., DeJong, W., \& Lepper, M. R. (1976). Effects of externally imposed deadlines on subsequent intrinsic motivation. Journal of Personality and Social Psychology, 34(1), 92.

Ariely, D., \& Wertenbroch, K. (2002). Procrastination, deadlines, and performance: Self-control by precommitment. Psychological Science, 13(3), 219-224. https://doi.org/10.1111/1467-9280.00441

Atkinson, J. W. (1974). Motivational determinants of intellective performance and cumulative achievement. In Motivation and achievement (pp. 389-410). V. W. Winston and Sons.

Atkinson, J. W. (1981). Thematic apperceptive measurement of motivation in 1950 and 1980. In G. D'Ydewalle \& W. Lens (Eds.), Cognition in human motivation and learning (pp. 159-198). Erlbaum.

Bauer, D. J., \& Curran, P. J. (2005). Probing interactions in fixed and multilevel regression: Inferential and graphical techniques. Multivariate Behavioral Research, 40(3), 373-400.

Beery, R. G. (1975). Special feature: Fear of failure in the student experience. The Personnel and Guidance Journal, 54(4), 191-203.

Belenky, D. M., \& Nokes-Malach, T. J. (2013). Mastery-approach goals and knowledge transfer: An investigation into the effects of task structure and framing instructions. Learning and Individual Differences, 25, 21-34.

Bies-Hernandez, N. J. (2012). The effects of framing grades on student learning and preferences. Teaching of Psychology, 39(3), 176-180.

Bjørnebekk, G., \& Gjesme, T. (2009). Motivation and temporal distance: Effect on cognitive and affective manifestations.
Psychological Reports, 105(2), 339-360. https://doi.org/10.2466/ PR0.105.2.339-360

Blasiman, R. N., Dunlosky, J., \& Rawson, K. A. (2017). The what, how much, and when of study strategies: Comparing intended versus actual study behaviour. Memory, 25(6), 784-792. https://doi.org/ 10.1080/09658211.2016.1221974

Brassler, N. K., Grund, A., Hilckmann, K., \& Fries, S. (2016). Impairments in learning due to motivational conflict: Situation really matters. Educational Psychology, 36(7), 1323-1336. https://doi. org/10.1080/01443410.2015.1113235

Britt, T. W. (2005). The effects of identity-relevance and task difficulty on task motivation, stress, and performance. Motivation and Emotion, 29(3), 189-202.

Burgess, M., Enzle, M. E., \& Schmaltz, R. (2004). Defeating the potentially deleterious effects of externally imposed deadlines: Practitioners' rules-of-thumb. Personality and Social Psychology Bulletin, 30(7), 868-877.

Canning, E. A., Priniski, S. J., \& Harackiewicz, J. M. (2019). Unintended consequences of framing a utility-value intervention in two-year colleges. Learning and Instruction, 62, 37-48.

Cardetti, F., \& McKenna, P. J. (2011). In their own words: Getting pumped for calculus. Primus, 21(4), 351-363.

Curran, P. J., Obeidat, K., \& Losardo, D. (2010). Twelve frequently asked questions about growth curve modeling. Journal of Cognition and Development, 11(2), 121-136.

Deci, E. L. (1971). Effects of externally mediated rewards on intrinsic motivation. Journal of Personality and Social Psychology, 18(1), 105

Deci, E. L., \& Ryan, R. M. (2012). Self-determination theory. In P. A. M. Van Lange, A. W. Kruglanski, \& E. T. Higgins (Eds.), Handbook of theories of social psychology (pp. 416-436). Sage.

De Ridder, D. T., Lensvelt-Mulders, G., Finkenauer, C., Stok, F. M., \& Baumeister, R. F. (2012). Taking stock of self-control: A metaanalysis of how trait self-control relates to a wide range of behaviors. Personality and Social Psychology Review, 16(1), 76-99.

Dewitte, S., \& Schouwenburg, H. C. (2002). Procrastination, temptations, and incentives: The struggle between the present and the future in procrastinators and the punctual. European Journal of Personality, 16(6), 469-489.

Dietrich, J., Moeller, J., Guo, J., Viljaranta, J., \& Kracke, B. (2019). In-the-moment profiles of expectancies, task values, and costs. Frontiers in Psychology, 10, 1662. https://doi.org/10.3389/fpsyg. 2019.01662

Dietrich, J., Viljaranta, J., Moeller, J., \& Kracke, B. (2017). Situational expectancies and task values: Associations with students' effort. Learning and Instruction, 47, 53-64. https://doi.org/10.1016/j. learninstruc.2016.10.009

Dresel, M., \& Grassinger, R. (2013). Changes in Achievement Motivation among University Freshmen. Journal of Education and Training Studies, 1(2), 159-173.

Dweck, C. S. (2017). From needs to goals and representations: Foundations for a unified theory of motivation, personality, and development. Psychological Review, 124(6), 689-719.

Eccles, J. S. (1983). Expectancies, values, and academic behaviors. In Achievement and achievement motives. Free man.

Eccles, J. S., \& Wigfield, A. (2020). From expectancy-value theory to situated expectancy-value theory: A developmental, social cognitive, and sociocultural perspective on motivation. Contemporary Educational Psychology, 61, 101859.

Elliot, A. J. (2006). The hierarchical model of approach-avoidance motivation. Motivation and Emotion, 30(2), 111-116.

Elliot, A. J., \& Covington, M. V. (2001). Approach and avoidance motivation. Educational Psychology Review, 13(2), 73-92.

Feltman, R., \& Elliot, A. J. (2012). Approach and avoidance motivation. Encyclopedia of the Sciences of Learning, 13, 286-288. 
Ferrari, J. R., Johnson, J. L., \& McCown, W. G. (1995). Procrastination and task avoidance: Theory, research, and treatment. Springer.

Ferrari, J. R., \& Tice, D. M. (2000). Procrastination as a self-handicap for men and women: A task-avoidance strategy in a laboratory setting. Journal of Research in Personality, 34(1), 73-83.

Fishbach, A., Zhang, Y., \& Koo, M. (2009). The dynamics of self-regulation. European Review of Social Psychology, 20(1), 315-344. https://doi.org/10.1080/10463280903275375

Flake, J. K., Barron, K. E., Hulleman, C., McCoach, B. D., \& Welsh, M. E. (2015). Measuring cost: The forgotten component of expectancy-value theory. Contemporary Educational Psychology, 41, 232-244.

Fleeson, W. (2007). Situation-based contingencies underlying traitcontent manifestation in behavior. Journal of Personality, 75, 825-861. https://doi.org/10.1111/j.1467-6494.2007.00458.x

Fries, S., \& Dietz, F. (2007). Learning in the Face of Temptation: The Case of Motivational Interference. The Journal of Experimental Education, 76(1), 93-112. https://doi.org/10.3200/ JEXE.76.1.93-112

Fries, S., Dietz, F., \& Schmid, S. (2008). Motivational interference in learning: The impact of leisure alternatives on subsequent self-regulation. Contemporary Educational Psychology, 33(2), 119-133. https://doi.org/10.1016/j.cedpsych.2007.10.001

Fries, S., Schmid, S., Dietz, F., \& Hofer, M. (2005). Conflicting values and their impact on learning. European Journal of Psychology of Education, 20(3), 259-273.

Fujita, K. (2011). On conceptualizing self-control as more than the effortful inhibition of impulses. Personality and Social Psychology Review, 15(4), 352-366.

Furr, R. M., \& Funder, D. C. (2018). Persons, situations, and personsituation interactions. In Handbook of personality: Theory and research, (Vol. 4). Guilford.

Geiser, C. (2011). Datenanalyse mit Mplus. VS Verlag für Sozialwissenschaften.

Gjesme, T. (1975). Slope of gradients for performance as a function of achievement motive, goal distance in time, and future time orientation. The Journal of Psychology, 91(1), 143-160.

Grund, A. (2013). Motivational profiles in study-leisure conflicts: Quality and quantity of motivation matter. Learning and Individual Differences, 26, 201-211.

Grund, A., Brassler, N. K., \& Fries, S. (2014). Torn between study and leisure: How motivational conflicts relate to students' academic and social adaptation. Journal of Educational Psychology, 106(1), 242-257. https://doi.org/10.1037/a0034400

Grund, A., \& Fries, S. (2012). Motivational interference in study-leisure conflicts: How opportunity costs affect the self-regulation of university students. Educational Psychology, 32(5), 589612. https://doi.org/10.1080/01443410.2012.674005

Grund, A., \& Fries, S. (2014). Study and leisure interference as mediators between students' self-control capacities and their domain-specific functioning and general well-being. Learning and Instruction, 31, 23-32. https://doi.org/10.1016/j.learninstr uc.2013.12.005

Grund, A., Grunschel, C., Bruhn, D., \& Fries, S. (2015). Torn between want and should: An experience-sampling study on motivational conflict, well-being, self-control, and mindfulness. Motivation and Emotion, 39(4), 506-520. https://doi.org/ 10.1007/s11031-015-9476-z

Heckhausen, J. (2020). Integrating and instigating research on person and situation, motivation and volition, and their development. Motivation Science, 6(3), 185-188.

Heckhausen, H., \& Gollwitzer, P. M. (1987). Thought contents and cognitive functioning in motivational versus volitional states of mind. Motivation and Emotion, 11(2), 101-120.

Hofer, M., \& Fries, S. (2016). A multiple goals perspective on academic motivation. In Handbook of motivation at school (2nd ed., pp. 452-470). Routledge. https://doi.org/10.4324/97813 15773384-30

Hofer, M., Schmid, S., Fries, S., Dietz, F., Clausen, M., \& Reinders, H. (2007). Individual values, motivational conflicts, and learning for school. Learning and Instruction, 17(1), 17-28. https:// doi.org/10.1016/j.learninstruc.2006.11.003

Hofmann, W., Friese, M., \& Strack, F. (2009). Impulse and selfcontrol from a dual-systems perspective. Perspectives on Psychological Science, 4(2), 162-176.

Howell, A. J., Watson, D. C., Powell, R. A., \& Buro, K. (2006). Academic procrastination: The pattern and correlates of behavioural postponement. Personality and Individual Differences, 40(8), 1519-1530. https://doi.org/10.1016/j.paid.2005.11.023

Hull, C. L. (1932). The goal-gradient hypothesis and maze learning. Psychological Review, 39(1), 25-43. https://doi.org/10.1037/ h0072640

Jackson, J. W. (2002). Enhancing self-efficacy and learning performance. The Journal of Experimental Education, 70(3), 243-254.

Kaplan, A., \& Maehr, M. L. (2007). The contributions and prospects of goal orientation theory. Educational Psychology Review, 19(2), 141-184.

King, R. B., \& Gaerlan, M. J. (2013). To study or not to study? Investigating the link between time perspectives and motivational interference. Journal of Pacific Rim Psychology, 7(2), 63-72. https:// doi.org/10.1017/prp.2013.8

König, C. J., \& Kleinmann, M. (2005). Deadline rush: A time management phenomenon and its mathematical description. The Journal of Psychology, 139(1), 33-45. https://doi.org/10.3200/JRLP. 139.1.33-45

Kosovich, J. J., Flake, J. K., \& Hulleman, C. S. (2017). Short-term motivation trajectories: A parallel process model of expectancyvalue. Contemporary Educational Psychology, 49, 130-139. https://doi.org/10.1016/j.cedpsych.2017.01.004

Kuhnle, C., Hofer, M., \& Kilian, B. (2010). The relationship of value orientations, self-control, frequency of school-leisure conflicts, and life-balance in adolescence. Learning and Individual Differences, 20(3), 251-255. https://doi.org/10.1016/j.lindif.2010. 02.003

Kurzban, R., Duckworth, A., Kable, J. W., \& Myers, J. (2013). An opportunity cost model of subjective effort and task performance. Behavioral and Brain Sciences, 36(6), 661-679.

Lewin, K. (1942). Field theory and learning. In N. B. Henry (Ed.), The forty-first yearbook of the National Society for the Study of Education: Part 2, The psychology of learning (pp. 215-242). University of Chicago Press. https://doi.org/10.1037/11335-006

Lewis, N. A., \& Oyserman, D. (2015). When does the future begin? Time metrics matter, connecting present and future selves. Psychological Science, 26(6), 816-825. https://doi.org/10.1177/ 0956797615572231

Liberman, N., Sagristano, M. D., \& Trope, Y. (2002). The effect of temporal distance on level of mental construal. Journal of Experimental Social Psychology, 38(6), 523-534. https://doi.org/10. 1016/S0022-1031(02)00535-8

Liberman, N., \& Trope, Y. (1998). The role of feasibility and desirability considerations in near and distant future decisions: A test of temporal construal theory. Journal of Personality and Social Psychology, 75(1), 5-18. https://doi.org/10.1037/0022-3514.75.1.5

Liborius, P., Bellhäuser, H., \& Schmitz, B. (2019). What makes a good study day? An intraindividual study on university students' time investment by means of time-series analyses. Learning and Instruction, 60, 310-321.

Loewenstein, G., \& Prelec, D. (1992). Anomalies in intertemporal choice: Evidence and an interpretation. The Quarterly Journal of Economics, 107(2), 573-597. 
Lorah, J. (2018). Effect size measures for multilevel models: Definition, interpretation, and TIMSS example. Large-Scale Assessments in Education, 6(1), 1-11.

Maas, C. J. M., \& Hox, J. J. (2005). Sufficient sample sizes for multilevel modeling. Methodology, 1(3), 86-92. https://doi.org/10. 1027/1614-2241.1.3.86

MacKillop, J., Amlung, M. T., Few, L. R., Ray, L. A., Sweet, L. H., \& Munafò, M. R. (2011). Delayed reward discounting and addictive behavior: A meta-analysis. Psychopharmacology (berl), 216(3), 305-321.

Mischel, W. (1977). The interaction of person and situation. In D. Magnusson \& N. S. Endler (Eds.), Personality at the cross-roads: Current issues in interactional psychology (pp. 333-352). Lawrence Erlbaum.

Muthén, L. K., \& Muthén, B. O. (2017). Mplus user's guide (19982017). Muthén \& Muthén.

Naujoks, N., \& Händel, M. (2020). Nur vertiefen oder auch wiederholen? Differenzielle Verläufe kognitiver Lernstrategien im Semester. Unterrichtswissenschaft, 48(2), 221-241.

Nezlek, J. B. (2012). Multilevel modeling for psychologists. In H. Cooper, P. M. Camic, D. L. Long, A. T. Panter, D. Rindskopf, \& K. J. Sher (Eds.), APA handbooks in psychology®. APA handbook of research methods in psychology, Vol. 3. Data analysis and research publication (pp. 219-241). American Psychological Association. https://doi.org/10.1037/13621-011

Paccagnella, O. (2011). Sample size and accuracy of estimates in multilevel models. Methodology, 7, 111-120. https://doi.org/10.1027/ 1614-2241/a000029

Peetz, J., \& Wilson, A. E. (2013). The post-birthday world: Consequences of temporal landmarks for temporal self-appraisal and motivation. Journal of Personality and Social Psychology, 104(2), 249.

Peetz, J., Wilson, A. E., \& Strahan, E. J. (2009). So far away: The role of subjective temporal distance to future goals in motivation and behavior. Social Cognition, 27(4), 475-495. https://doi.org/10. 1521/soco.2009.27.4.475

Pintrich, P. R. (2000). An achievement goal theory perspective on issues in motivation terminology, theory, and research. Contemporary Educational Psychology, 25(1), 92-104.

Putwain, D., \& Remedios, R. (2014). The scare tactic: Do fear appeals predict motivation and exam scores? School Psychology Quarterly, 29(4), 503-516.

Ratelle, C. F., Senecal, C., Vallerand, R. J., \& Provencher, P. (2005). The relationship between school-leisure conflict and educational and mental health indexes: A motivational analysis. Journal of Applied Social Psychology(35). Article, 9, 1800-1822. https:// doi.org/10.1111/j.1559-1816.2005.tb02196.x

Reeve, J. (2016). A grand theory of motivation: Why not? Motivation and Emotion, 40(1), 31-35.

Riediger, M., \& Freund, A. M. (2008). Me against myself: Motivational conflicts and emotional development in adulthood. Psychology and Aging, 23(3), 479-494. https://doi.org/10.1037/a0013302

Robinson, K. A., Lee, Y. K., Bovee, E. A., Perez, T., Walton, S. P., Briedis, D., \& Linnenbrink-Garcia, L. (2019). Motivation in transition: Development and roles of expectancy, task values, and costs in early college engineering. Journal of Educational Psychology, 111(6), 1081.

Rottweiler, A. L., Taxer, J. L., \& Nett, U. E. (2018). Context matters in the effectiveness of emotion regulation strategies. AERA Open, $4(2), 2332858418778849$

Rubinstein, A. (2003). "Economics and psychology"? The case of hyperbolic discounting. International Economic Review, 44(4), $1207-1216$

Schouwenburg, H. C., \& Groenewoud, J. (2001). Study motivation under social temptation; effects of trait procrastination. Personality and Individual Differences, 30(2), 229-240.
Schoeneberger, J. A. (2016). The impact of sample size and other factors when estimating multilevel logistic models. The Journal of Experimental Education, 84(2), 373-397. https://doi.org/10. 1080/00220973.2015.1027805

Simons, J., Vansteenkiste, M., Lens, W., \& Lacante, M. (2004). Placing motivation and future time perspective theory in a temporal perspective. Educational Psychology Review, 16(2), 121-139.

Soman, D., Ainslie, G., Frederick, S., Li, X., Lynch, J., Moreau, P., \& Wertenbroch, K. (2005). The psychology of intertemporal discounting: Why are distant events valued differently from proximal ones? Marketing Letters, 16(3-4), 347-360.

Sommet, N., \& Morselli, D. (2017). Keep calm and learn multilevel logistic modeling: A simplified three-step procedure using Stata, R, Mplus, and SPSS. International Review of Social Psychology, 30(1), 203-218. https://doi.org/10.5334/irsp.90

Steel, P. (2007). The nature of procrastination: A meta-analytic and theoretical review of quintessential self-regulatory failure. Psychological Bulletin, 133(1), 65-94. https://doi.org/10.1037/00332909.133.1.65

Steel, P., \& König, C. (2006). Integrating theories of motivation. Academy of Management Review, 31, 889-913.

Tang, S. H., \& Hall, V. C. (1995). The overjustification effect: A metaanalysis. Applied Cognitive Psychology, 9(5), 365-404.

Taraban, R., Maki, W. S., \& Rynearson, K. (1999). Measuring study time distributions: Implications for designing computer-based courses. Behavior Research Methods, Instruments, \& Computers, 31(2), 263-269.

Trope, Y., \& Liberman, N. (2003). Temporal construal. Psychological Review, 110(3), 403-421.

Trope, Y., \& Liberman, N. (2010). Construal-level theory of psychological distance. Psychological Review, 117(2), 440-463. https:// doi.org/10.1037/a0018963

Trope, Y., Liberman, N., \& Wakslak, C. (2007). Construal levels and psychological distance: Effects on representation, prediction, evaluation, and behavior. Journal of Consumer Psychology, 17(2), 83-95.

Trull, T. J., \& Ebner-Priemer, U. (2014). The role of ambulatory assessment in psychological science. Current Directions in Psychological Science, 23(6), 466-470. https://doi.org/10.1177/09637 21414550706

Vallerand, R. J., Pelletier, L. G., Blais, M. R., Briere, N. M., Senecal, C., \& Vallieres, E. F. (1992). The Academic Motivation Scale: A measure of intrinsic, extrinsic, and amotivation in education. Educational and Psychological Measurement, 52(4), 1003-1017.

Vansteenkiste, M., Simons, J., Lens, W., Soenens, B., \& Matos, L. (2005). Examining the motivational impact of intrinsic versus extrinsic goal framing and autonomy-supportive versus internally controlling communication style on early adolescents' academic achievement. Child Development, 76(2), 483-501.

Vansteenkiste, M., Timmermans, T., Lens, W., Soenens, B., \& Van den Broeck, A. (2008). Does extrinsic goal framing enhance extrinsic goal-oriented individuals' learning and performance? An experimental test of the match perspective versus self-determination theory. Journal of Educational Psychology, 100(2), 387.

Wang, L., Zhang, Q., Maxwell, S. E., \& Bergeman, C. S. (2019). On standardizing within-person effects: Potential problems of global standardization. Multivariate Behavioral Research, 54(3), 382-403.

Wigfield, A., \& Cambria, J. (2010). Expectancy-value theory: Retrospective and prospective. Theoretical perspectives on motivation and achievement. Emerald Group Publishing Limited.

Wigfield, A., \& Eccles, J. S. (2000). Expectancy-value theory of achievement motivation. Contemporary Educational Psychology, 25(1), 68-81.

Wolters, C. A. (2004). Advancing achievement goal theory: Using goal structures and goal orientations to predict students' motivation, 
cognition, and achievement. Journal of Educational Psychology, 96(2), 236-250. https://doi.org/10.1037/0022-0663.96.2.236

Wolters, C. A., \& Rosenthal, H. (2000). The relation between students' motivational beliefs and their use of motivational regulation strategies. International Journal of Educational Research, 33(7-8), 801-820.

Yarkoni, T. (2019). The generalizability crisis. Preprint. PsyArXiv. https://doi.org/10.31234/osf.io/jqw35
Publisher's Note Springer Nature remains neutral with regard to jurisdictional claims in published maps and institutional affiliations. 